\title{
LA JERARQUÍA DE REMEDIOS EN LA COMPRAVENTA DE CONSUMO A PARTIR DE SUS LÍMITES CIVILES Y TRIBUTARIOS
}

\author{
HIERARCHY OF REMEDIES IN THE CONSUMER SALES CONTRACT \\ FROM ITS CIVIL AND TAX LIMITS
}

\begin{abstract}
Alfredo Ferrante*
RESUMEN: El artículo ofrece una interpretación que permite sistematizar los medios de tutela del consumidor en la compraventa. Se destaca que la interacción de la normativa tributaria con la civil crea una serie de modelos de jerarquía remedial, pese a que la literalidad de la ley de consumo chilena ofrezca la libre elección al comprador.

Palabras clave: Compraventa, consumidor, remedios, reparación, resolución.

ABSTRACT: The paper offers an interpretation that allows systematizing the remedies in the consumer sales contracts. It emphasizes that the interaction of tax regulations with civil law creates a series of models of hierarchy of remedies despite the fact that the literality of the Consumer Law of Chile offers a free choice of resources to the buyer.
\end{abstract}

Key words: sales contract, consumer, remedies, repair, termination of contract.

\section{INTRODUCCIÓN Y PLANTEAMIENTO}

Entre los derechos previstos en favor del comprador en caso de disconformidad material, los arts. 20 y 21 de la ley sobre protección de los derechos de los consumidores ${ }^{1}$ prevén, el reemplazo del bien, su reparación o la posibilidad de solicitar la devolución de la cantidad pagada, remedio este último que la doctrina ha asociado con la resolución del contrato $^{2}$. Esta "triple opción” ${ }^{3}$, sin embargo, debe analizarse con más profundidad, puesto

\footnotetext{
* Doctor Europeo en Derecho Civil cum laude por la Universidad de Oviedo. Profesor de Derecho Civil en la Universidad Alberto Hurtado. Dirección postal: Almirante Barroso No 10, Santiago de Chile, Chile. Dirección electrónica: aferrante@uahurtado.cl.

La presente publicación se enmarca en el proyecto Fondecyt No 1171251, del cual el autor es investigador responsable.

1 Ley No 19.496 de 1997, donde no se haya especificado la referencia a las disposiciones citadas, debe entenderse que corresponden a esta ley. Sobre ella véase: Fernández (2003); Aimone (2013), Pizarro y De la Maza (dir.) BARrientos (coord.) (2013), BARRIENTOS et al. (2013).

2 Por todos Barrientos (2016) p. 202; Barrientos (2018) p. 358; Corral (2006) p. 97, nota No 3; Corral (2011) p. 117, nota 141. Para efectos de este trabajo se utilizará de manera indiferente la "devolución de la cantidad pagada" y la "resolución del contrato". Además, se considerará también como equivalentes las expresiones "medio de tutela" y "remedio".

3 Definida de esta forma, la define así la doctrina, Aimone (2013) p. 47, repetidamente en Barrientos (2016), Corral (2006) p. 98; NASSER (2013) p. 548; lo mismo hace la jurisprudencia SERVICIO NACIONAL DEL ConsumIDOR CON HITES (2012).
} 
que la normativa a la cual se hace referencia se caracteriza por disponer, en el penúltimo inciso del art. 21, una regla exclusiva para la devolución de la cantidad pagada.

En efecto, en este caso se establece ${ }^{4}$ que el plazo para ejercer la acción para solicitar la devolución de la cantidad pagada en caso de disconformidad material "se contará desde la fecha de la correspondiente factura o boleta", añadiendo que "no se suspenderá en caso alguno". Además, se hace una remisión expresa a sus tributos y concretamente a la ley sobre el impuesto a las ventas y servicios ${ }^{5}$, considerando, en determinados casos, la devolución de la suma sin el importe correspondiente al impuesto al valor agregado (en adelante IVA).

Puesto que la doctrina no ha analizado con particular detalle esta disposición ${ }^{6}$, estas líneas se ocuparán de la importancia práctica de dichos incisos y si ellos influyen sobre la tutela efectiva del comprador en caso de garantía legal ${ }^{7}$. Efectivamente la regulación de la resolución del contrato se viene a diferenciar de la de los demás remedios (cfr. inciso primero del art. $21^{8}$ ) y se caracteriza por hacer convivir la normativa estrictamente civil con la tributaria, a partir de la referencia a la boleta o factura.

El objetivo de este estudio es sistematizar y comprender el sistema remedial de la garantía legal viendo la interacción de la normativa tributaria con la civil para constatar si efectivamente existe una libre opción de remedios o más bien existen varios modelos, algunos de los cuales jerárquicos debido a la diferencia de plazos impuestos por las normas imponen que rinde así algunos remedios no disponibles en determinados casos.

La hipótesis que se plantea es que, a pesar de que la literalidad de Ley No 19.496 prevé una libre elección de remedios, manifestada en la "triple opción", esto no se produce siempre.

La metodología empleada será la revisión dogmática y positiva relativa a la normativa civil y tributaria, categorizando y comparándose los modelos que pueden darse.

El escrito, en primer lugar, sistematiza algunas características exclusivas de la garantía legal en relación con la normativa civil (II-V), para luego ver cómo incide el penúltimo inciso del art. 21 y sus referencias tributarias (VI-VII), analizando también el peculiar caso de los bienes perecibles (VIII), finalizando con alguna conclusión.

\section{LAS INTERFERENCIAS DE CARÁCTER CIVIL SOBRE LA LIBRE ELECCIÓN DE LOS REMEDIOS}

A partir del aspecto estrictamente civil, cabe preguntarse si la regulación de la garantía legal es coherente con lo que ahí se consagra o la realidad es otra. Por ello, debe exami-

\footnotetext{
4 Art. 21, inciso 11º: "Tratándose de la devolución de la cantidad pagada el plazo para ejercer la acción se contará desde la fecha de la correspondiente factura o boleta y no se suspenderá en caso alguno. Si tal devolución se acordare una vez expirado el plazo a que se refiere el artículo 70 del decreto Ley No 825, de 1974, el consumidor solo tendrá derecho a recuperar el precio neto del bien, excluidos los impuestos correspondientes".

5 Correspondiente al Decreto Ley No 825 de 1974. En lo sucesivo ley sobre IVA.

6 Solo una parte de la doctrina ha abordado parcialmente el tema: Barrientos (2016) p. 209 y 210. También limitadamente véase Nasser (2013) pp. 551 y 552; Corral (1999) p. 175, nota 20, Corral (2011) p. 124 y 125, CoRral (2006) p. 101-102.

7 Sobre la garantía legal, por todos, remítase a la obra monográfica de BARRIENTOS (2016).

8 Quedará fuera de este escrito otra diferenciación, prevista por el inciso quinto del art. 21, de acuerdo con la cual, la devolución de la cantidad pagada puede intentarse solo respecto del vendedor. Tampoco se analizarán la
} 
narse si efectivamente se materializa la libre elección en favor del comprador -declarada en el primer inciso del art. 20- entre la reparación gratuita del bien, su sustitución o la resolución, armonizando así la expresión "podrá optar" con la práctica.

De un examen efectuado a lo que ocurre al aplicar estos remedios, esencialmente parecen encontrarse dos límites de naturaleza civil: el primero, se relaciona con la imposibilidad de suspender el plazo en caso de resolución (II.A), y el otro, se refiere a un diferente cómputo del mismo, para ejercer la llamada garantía legal (II.B).

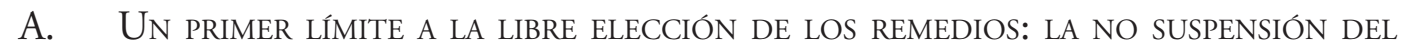
PLAZO EN CASO DE RESOLUCIÓN

El penúltimo inciso del art. 21 indica con claridad que el plazo de ejercicio para la devolución de la cantidad pagada "no se suspenderá en caso alguno", aspecto no previsto por la reparación y sustitución.

Este inciso puede considerarse un límite intrínseco al ejercicio del derecho, tanto cuando se presenta una garantía convencional ${ }^{9}$, como respecto de la libre elección de los remedios que provienen de la garantía legal.

Efectivamente, de acuerdo con lo dispuesto en la Ley No 19.946 no podría hacerse valer para la devolución de la cantidad pagada la posibilidad de suspensión prevista en caso de reparación (inciso octavo del art. $21^{10}$ ), ni siquiera gracias a la posibilidad que otorga la interposición de un reclamo frente al respectivo órgano (véase inciso segundo art. 26) ${ }^{11}$.

Una vez admitida la independencia ${ }^{12}$ de la acción contravencional y de la civil se podrá producir la suspensión de la primera en relación con el plazo del art. 26, pero no respecto de la acción civil derivada de la devolución de la cantidad pagada ${ }^{13}$. Esta diferencia

cuestión relativa al quantum con referencia a la devolución del precio neto en relación con la devolución de la cantidad pagada y ni tampoco el último inciso del artículo relativo a la prueba de la boleta o factura.

9 La doctrina la ha considerado como un límite cuando "existan otras garantías paralelas": BARRIENTOS (2016) p. 210.

10 De acuerdo con el cual: "el plazo que la póliza de garantía otorgada por el proveedor contemple y aquel a que se refiere el inciso primero de este artículo, se suspenderán durante el tiempo en que el bien esté siendo reparado en ejercicio de la garantía”.

11 De hecho, dado que existe independencia entre la acción contravencional y aquella civil, es que no se puede acudir a las excepciones a la prescripción que derivan de la primera, para evitar que sea declarada extinguida la segunda, en que se pidió la devolución del precio: CASTILlo ACUÑA LUIS CON Automotora PRIME (2011).

12 Debe constatarse que el tema no ha sido pacífico; aquí es útil observar cómo Corral ya constaba que: "en el pre-proyecto del Ministerio de Economía el plazo de prescripción de seis meses se aplicaba a todas 'las acciones que persigan la responsabilidad por las contravenciones que se sancionan por la presente Ley’. El Proyecto varió la norma para disponer que la prescripción se aplicaba a 'las acciones que persigan la responsabilidad contravencional', y con ello obviamente restringió el sentido de la disposición. Hay indicios que el legislador quiso dejar la prescripción de la acción civil sometida a las normas comunes": así y más ampliamente CorraL (1999) nota a pie de página No 68, p. 209.

En relación con el plazo, obsérvese que este podría ser calificado de prescripción o caducidad: por ejemplo, véase BARCia (20112) p. 115 y ss; recientemente también sobre el inicio del cómputo del plazo Ferrante (2018C) p. 438 y ss.

13 Como ocurre cuando se declara la excepción de prescripción en la compraventa de un mueble bar de madera

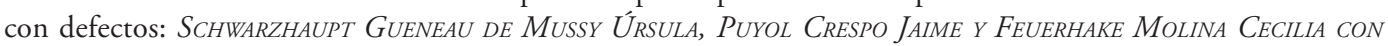
COMERCIALIZADORA EL REGUE LIMITADA (2016). 
ampliaría las posibilidades de demandar la reparación o la sustitución del bien (que admiten la suspensión), por oposición a lo que ocurre con la restitución de lo pagado, remedio que ya no se encontraría disponible.

Frente a esta solución que altera y reduce la tutela del consumidor, cabe destacar el esfuerzo que han hecho los tribunales por interpretar estas reglas con mayor fidelidad a la protección efectiva del comprador, prescindiendo de una lectura ortodoxa que, de imposibilitar la suspensión del plazo, alteraría sus máximas de resguardo. En este sentido, y al margen de rechazar peticiones extemporáneas ${ }^{14}$, pueden evidenciarse cuatro posturas jurisprudenciales que han evitado limitar la devolución del precio debido a la rigidez de la norma.

Una primera vía de solución se encuentra en el marco de una tendencia más general que busca obviar el corto plazo de la garantía legal, procediendo a aplicarle el plazo, más amplio, si es que existe una garantía convencional ${ }^{15}$. Así, se puede reclamar igualmente una devolución por haberse vendido el producto con garantía por un año ${ }^{16}$.

Una segunda tendencia es proceder a aplicar al remedio un diferente comienzo de plazo, de modo que, pese a que no se pueda suspender, se computaría desde el momento "en que se presenta la última falla"17.

Además de estas técnicas, pueden identificarse dos clases de argumentaciones que, en concreto, defienden una libre elección entre la reparación, sustitución y devolución de la cantidad pagada, junto con la posible opción por el remedio de la resolución, sobre todo, después de una reparación infructuosa.

La primera de ellas (y tercera postura jurisprudencial en general), es sostener que el plazo para pedir la devolución del precio se compute desde que termine la eventual reparación solicitada. Esta lectura ha garantizado la efectividad de la "triple opción" y hace de la restitución un remedio aplicable cuando la reparación demore más de tres meses. Lo anterior, evita así también el incentivo por recurrir directamente a la devolución de la cantidad pagada, debido al riesgo de que una excesiva tardanza en la reparación impida el ejercicio posterior del remedio, que se encontraría prescrito.

Siguiendo esta lógica en un caso de una lavadora que fue infructuosamente reparada tres veces, se ha considerado que "la triple opción legal (omissis) nace para el consumidor, en el caso de la reparación de un producto, cada vez que vuelve a recepcionar el producto supuestamente reparado 18 ". Se argumenta que el hecho de que el producto no sea "reparado satisfactoriamente no puede ser sinónimo de que el consumidor pierda cualquier otro derecho de reclamo, salvo la posibilidad de hacer efectiva la garantía contra el fabricante ${ }^{19 ”}$.

\footnotetext{
14 En este caso, se había solicitado la devolución con fecha 15 de noviembre, respecto de una compraventa de audífonos celebrada el 14 de junio: RAMÓN ZAMBRANO MARDONES CON ÓPTICA ROTTER Y KRAUSS LIMITADA (2014).

${ }_{15}$ El interesante debate sobre cuál garantía debe primar, entre la garantía legal y convencional, queda fuera de este estudio.

16 Luis Pacheco Díaz con Cencosud Retail S.A. (2016).

17 En este caso concreto, frente al mal funcionamiento de un vehículo, la empresa ofreció dar en pago otro automóvil que también presentó defectos, debiéndose solicitar finalmente la devolución del importe pagado por el comprador: ISAIAS W. MALDONADO ARAVENA CON SEBASTIÁN FLORES CAÑAS (2016).

18 SerVicio NaCional del Consumidor con ComerCializadora S.A. (2012).

19 SerVicio NaCional del Consumidor con Comercializadora S.A. (2012).
} 
Así, considera como no prescrita la acción de devolución del precio, por cuanto "esta interpretación restrictiva, incluso podría ir en desmedro del libre ejercicio de este derecho, toda vez que los consumidores podrían abstenerse de hacer efectiva la opción de reparar el producto, sabiendo que basta que el producto quede mal reparado o simplemente el servicio técnico se demore más de 3 meses, para perder cualquier derecho como consumidor sobre el bien comprado ${ }^{20 "}$.

La segunda línea argumentativa (cuarta postura jurisprudencial en general), es la de proceder a una relectura de la frase "no se suspenderá", que favorezca un correcto equilibrio en la relación de consumo, aduciendo que dicho inciso "no puede sino entenderse e interpretarse bajo el supuesto natural y obvio de que el cliente se encuentre en condición de ejercer sus derechos, es decir la imposibilidad de no poder revisar el vehículo"21, o cualquier bien, en general. En este sentido, se admite la posibilidad de solicitar la devolución de la cantidad pagada después de haber trascurrido los tres meses y cuatro reparaciones inoperantes.

Esta forma de comprender la norma protege la libre elección de los remedios ab initio y elimina una redacción poco técnica de la disposición, a la luz de un correcto desarrollo de la relación de consumo que impone una tutela efectiva del consumidor. Por ello, se considera que "una interpretación diversa no solo atenta contra el principio de equilibrio que debe regir la relación entre proveedor y consumidor, sino que incluso resulta nociva para los intereses del comercio, pues pone a este último en la obligación de optar por la devolución del dinero o reposición del bien tan pronto como presente un desperfecto, por más mínima que fuere su entidad, a fin de no incurrir en la caducidad del plazo" ${ }^{22}$.

En definitiva, puede destacarse que, en aras de una tutela material del consumidor, la jurisprudencia ha intentado abatir el límite impuesto por una aplicación literal del impedimento de la suspensión del plazo en caso de resolución. Esto ofrece protección concreta, por ejemplo, frente a eventuales ausencias de respuesta por parte del vendedor o por plazos de reparación más amplios, en que tampoco se hayan corregido las deficiencias de los bienes sometidos a ella.

Por lo tanto, parece que, aunque este límite se manifiesta por el dictado expreso de la norma, se elimina de facto -o por lo menos se atenúa- gracias a aquella jurisprudencia que se encuentra atenta a la protección del sujeto débil.

B. UN SEGUNDO LÍMITE: DIFERENTE MOMENTO DE INICIO PARA EL EJERCICIO DEL REMEDIO

Aunque para todos los remedios se identifica un igual lapso de tiempo, tres meses, en concreto el art. 21 de la ley predispone un plazo de ejercicio diferente para las acciones que derivan de los remedios de reparación y sustitución respecto de la resolución, y que se manifiesta por el establecimiento de un diferente momento de inicio.

Efectivamente, a pesar de que el primer inciso del art. 20 afirma que para ejercer los remedios relacionados con la garantía legal -entendiéndose incluida la resolución del con-

\footnotetext{
20 SERVICIO NACIONAL DEL CONSUMIDOR CON COMERCIALIZADORA S.A. (2012).

${ }^{21}$ Viviana Bustos GuZmán con Automotora Gildemeister S.A. (2017). Se pidió la resolución después de acudir cuatro veces al servicio técnico sin éxito.

22 ViViana Bustos GuZmán con Automotora Gildemeister S.A. (2017).
} 
trato- su posible ejercicio se cuenta desde el momento de la entrega del bien, una interpretación coordinada con el penúltimo inciso del art. 21 exige rectificar este aspecto. De una lectura conjunta, tendría que concluirse que dicho término valdría solo para la reparación y la reposición del producto, ya que en el caso de devolución de la cantidad pagada, el plazo se computa "desde la fecha de la correspondiente factura o boleta". Es decir, si para la reparación y sustitución el inicio del plazo se fija al momento de entrega, para la resolución lo será desde la emisión de la boleta o factura.

Este inciso ha planteado ciertos interrogantes y se ha considerado que la norma "contempla una expresión difícil de interpretar" ${ }^{23}$; de modo que corresponde ahora dilucidar si de su interpretación pueden develarse algunos aspectos relacionados con la elección de los remedios de la "triple opción” de la garantía legal.

\section{PRIMERA PREMISA: LA LEY No 19.496 NO IDENTIFICA UN SISTEMA REMEDIAL DIFERENCIADO PARA LAS COMPRAVENTAS PRESENCIALES Y ON LINE}

En Chile, la compraventa del comercio electrónico no recibe una específica reglamentación ni en sus aspectos generales, ni tampoco se prevé un sistema de remedios particular en el caso de compraventas a distancia regidas por la Ley 19.496 ${ }^{24}$. Esta reglamentación exclusivamente prevé determinados aspectos que otorgan una mayor tutela en las transacciones electrónicas, como es la posibilidad de ejercer un derecho de retracto ${ }^{25}$.

Frente a este panorama, debería evaluarse si la compraventa electrónica puede o no considerarse una contratación a distancia. A favor de ella son útiles las limitadas referencias que se realizan en la ley sobre protección de derecho de los consumidores y que presuponen lo afirmado. Efectivamente, los arts. 12 A y 32 consideran la existencia de "los contratos celebrados por medios electrónicos (omissis) y (o) cualquier otra forma de comunicación a distancia", reconociendo esta tipología de contrato una especie dentro del género.

Aunque haya una parte de la doctrina que se pronuncia en contra de la literalidad de esta normativa y enmarca los contratos electrónicos dentro de la compraventa presencial ${ }^{26}$, debería propenderse a lo contrario ya que, aunque pueda existir cercanía física de los contratantes en el momento de la contratación, el consentimiento y el medio utilizado presupone características particulares que la distinguen de la presencial.

\footnotetext{
23 En este sentido Barrientos (2016) p. 209.

24 Frente a esta situación, la doctrina se ha esforzado por reconstruir el contenido de algunos vacíos, tales como la formación del consentimiento. Por todos Pinochet (2004, 2005A, 2005B) Pinochet y Aguirre, (2006). No obstante, sí existen leyes que se dedican a aspectos relacionados, como la Ley No 19.799 de 2002.

25 Aunque esta igualmente podría excluirse por el vendedor en las condiciones generales del contrato (cfr. art. 3 bis letra b). En general, sobre dicha disposición véase Prado (2013), Pinochet (2013A). Sobre el derecho de retracto en relación con un contrato electrónico véase ZEPEDA DUHALDE, MARNA CON VIAJES FALABELLA S.A. Y OTRO (2017).

26 Pinochet (2013A) pp. 176-178.
} 


\section{SEGUNDA PREMISA: LA REMISIÓN DE LA LEY No 19.496 A LA FACTURA Y BOLETA CREA DOS MODELOS DE TUTELA DIFERENTES}

Ahora bien, tampoco la ley sobre IVA distingue entre compraventa presencial y a distancia; sin embargo, la interpretación conjunta de la normativa civil y tributaria ${ }^{27}$ conduce a relevantes diferencias que impiden aplicar de facto la misma tutela remedial a ambos tipos de venta.

La reglamentación tributaria, impone la emisión de la boleta o factura en el momento de la entrega real o ficticia del bien ${ }^{28}$ o, si esto no se produce, en el caso de la factura luego de que se haya emitido la guía de despacho ${ }^{29}$. De esta forma, aunque en la mayoría de los casos de compraventas de bienes muebles la celebración del contrato coincida con la entrega y la emisión de la boleta o factura, ello no siempre es así. Este aspecto es clave y requiere ser analizado, principalmente porque el plazo para ejercer los remedios de sustitución y reparación se computa desde la entrega del objeto (cfr. primer inciso art. 21), mientras que, en el caso de la resolución, se cuenta desde la emisión de la boleta o factura.

Por lo tanto, es menester asumir la posibilidad de que se presenten dos escenarios I) en el primero, la celebración de la compraventa coincide con la entrega del bien; II) en el segundo, la celebración del contrato y la entrega del bien no coinciden y por ello hay un desfase temporal entre ambos momentos; situación que plantea la duda acerca de cómo interacciona lo dicho con las tipologías de compraventa presencial y a distancia (u online) y la garantía legal. Aunque el primer caso debería asociarse naturalmente con las compraventas presenciales, y el segundo con aquellas a distancia y online, esto no siempre es así. Por lo anterior, se hace necesario sistematizar dos modelos.

De acuerdo con un primer modelo, que se denominará alfa, el día en que se comienza a computar el ejercicio de la reparación o sustitución será idéntico a aquel para pedir la resolución ${ }^{30}$. Aquí habrá certeza absoluta acerca del momento en que comienza a contabilizarse el plazo para todos los remedios derivados de la garantía legal, pues el momento de la entrega del bien coincidirá con la emisión de la factura. Esta situación podría presentarse en tres casos: en toda compraventa presencial con una contextual entrega del bien; en aquella presencial o a distancia en que la entrega se verifica dentro del mismo día, aunque haya sido aplazada respecto de la celebración del $\operatorname{contrato}^{31}$; y finalmente, en todos los casos de compraventas online y a distancia en que la facturación se haga al momento de la entrega efectiva del objeto.

A este modelo se contrapone otro, que se llamará beta, en el que la fecha de emisión de la factura o boleta no es la misma de la entrega del bien. En este caso, por lo tanto, el

\footnotetext{
${ }^{27}$ En concreto cfr. art. 21 inciso primero y penúltimo de la ley No 19.496 de 1997, junto con los incisos primero, cuarto y sexto del art. 55 de la ley sobre IVA.

${ }^{28}$ Cfr. el primer y sexto inciso del art. 55 de la ley sobre IVA; véase también el art. 17 No 2 Decreto supremo No 66 de 1977 (en lo sucesivo Reglamento IVA): véase abajo VI.C.

29 Inciso quinto del art. 55 Ley sobre IVA.

30 Piénsese en un televisor comprado presencialmente por la mañana, en que se acuerda la entrega en el domicilio por la tarde del mismo día.

31 Cfr. art. 21 primer y penúltimo inciso; art. 55, primer y sexto inciso Ley sobre IVA.
} 
cómputo del plazo de reparación y la sustitución, y el de la resolución, no principiaría en el mismo momento. Esta situación se generará preponderantemente en las compraventas a distancia u online, en que las entregas están pospuestas (exceptuadas las hipótesis pertenecientes al modelo alfa). También en determinados casos de compraventa presencial, en que a) las partes acuerden la entrega del bien en un momento posterior al día de compra (por ejemplo, la adquisición presencial en un supermercado de un televisor o de productos alimenticios que no son entregados inmediatamente) o b) el bien no se encuentre momentáneamente en stock y por ello se esperará su llegada (por ejemplo, la compraventa de un bien en oferta donde el vendedor no ha especificado que se limita a un determinado número de ejemplares, debiendo responder ante el consumidor que ha comprado).

Ahora bien, desde el punto de vista de la garantía legal solamente es relevante el segundo caso, ya que no es posible identificar el bien. En el primero, incluso el momento de la celebración del contrato y de la entrega podrían coincidir, ya que, aunque la entrega material se realice en un día diferente, puede presentarse una ficticia al momento de emitir la factura, como ocurriría con la modalidad longa manu o si se seleccionaran los productos por el mismo comprador en la tienda. Dicha situación se produce porque la entrega material y la ficticia se equiparan, en la normativa tributaria, con el momento de la facturación.

A continuación, y habiendo aclarado que el modelo alfa y beta no siempre coinciden con las ventas presenciales y a distancia, se utilizarán igualmente ambos patrones, puesto que la mayoría de las hipótesis se identifican con ellos. De esta manera y para hacer una lectura más clara, en lo que sigue el escrito los asimilará, aunque debe siempre tenerse presente la aclaración recién mencionada. En consecuencia, cada vez que se aluda a las compraventas presenciales, se entenderá hecha la referencia al modelo alfa y en aquellas a distancia, al modelo beta.

\section{PRIMERA CONSTATACIÓN: EN LAS COMPRAVENTAS PRESENCIALES EXISTE LIBRE ELECCIÓN ENTRE LOS REMEDIOS RELATIVOS A LA GARANTÍA LEGAL}

A pesar de que la Ley 19.496 prevé un diferente momento de inicio para el ejercicio de los remedios, en las compraventas presenciales (más bien en el modelo alfa), en principio, el comprador siempre podrá elegir libremente la utilización de cualquiera de ellos. La única limitación que se podría vislumbrar en la práctica es la falta de interés por demandar la reparación o la sustitución, ya que el plazo para el ejercicio de la resolución no podría suspenderse según el tenor literal del art. 21. Con todo, se ha visto que la praxis jurisprudencial de facto ha contribuido a eliminar esta restricción (véase arriba II.A).

En definitiva, puede afirmarse que, en relación con las compraventas presenciales (modelo alfa), la triple elección a favor del comprador se verifica a partir de dos constataciones. Primeramente, mediante la identificación temporal de la entrega con la emisión de la factura, coincidiendo en el momento de inicio para el ejercicio de los remedios; y en segundo lugar, gracias a que los tribunales, ahí donde debería proceder, intentan no tomar en consideración la limitación relativa a la no suspensión del plazo de ejercicio de la resolución del contrato. 


\section{LAS REMISIONES AL DERECHO TRIBUTARIOY SU INCIDENCIA EN LA GARANTÍA LEGAL}

En relación con los aspectos tributarios de los remedios en materia de consumo, la doctrina ha hecho referencia a los potenciales problemas de la indemnización de daños y al hecho de que esta no puede considerarse renta ${ }^{32}$. Por su parte, se ha manifestado que, a diferencia del caso anterior, no habría mayores problemas en relación con el impuesto al valor agregado $^{33}$. Sin embargo, aquí se intentará demostrar la presencia de algunos problemas generados por la coexistencia de las normas fiscales con aquellas relativas a la garantía legal.

En concreto, el art. 21 realiza una referencia expresa y una indirecta a la normativa tributaria: la primera, en relación con el art. 70 del decreto No 825 de 1974, y la segunda, por la referencia a la emisión de la boleta o factura para computar el plazo de la acción de resolución. En concreto, se valorará si se producen restricciones a la pretendida libre elección de los derechos que tiene el consumidor frente a la compraventa de un bien con disconformidad material (VI.A-VI.C).

\section{A. LA INCIDENCIA A LA REFERENCIA A LA BOLETA O FACTURA EN LAS COMPRAVENTAS A DISTANCIA U ONLINE \\ En el caso de devolución de la cantidad pagada el plazo se computa "desde la fecha} de la correspondiente factura o boleta" ${ }^{34}$. De inmediato resalta que se haga referencia a la factura, ya que, por un lado, esta se emite para un contribuyente IVA que, por lo tanto, debe tener ánimo de reventa o de lucro. Y por otra parte, cabe destacar que la definición de consumidor no se aplica a las personas que habitualmente desarrollen actividades empresariales, sino a quien es el destinario final del bien ${ }^{35}$.

Sin embargo, la posibilidad de una utilización mixta del bien y la ampliación de una definición de consumidor a un concepto de sujeto débil, permiten enmarcar en tal categoría no solo a la persona física, sino que también a otros sujetos. Así, la jurisprudencia ha identificado como consumidores a la municipalidad que adquirió un camión recolector de contenedores $^{36}$, o a quien compró un software defectuoso que era destinado a maximizar los tiempos de sus empleados ${ }^{37}$. Por ello, la emisión de una factura no debe excluir por si sola la condición de consumidor, puesto que en determinados casos también el pequeño empresario u otros sujetos pueden considerarse como tales, todas las veces que sean los destinatarios finales del bien comprado.

\footnotetext{
32 Véase en general Montecinos (2007), también Escobar (2004).

33 Así Montecinos (2007) pp. 892 y 909.

34 A tenor del penúltimo inciso del art. 21 Ley No 19.496 de 1997.

35 Sobre la definición y el concepto de consumidor en la Ley 19.496 MomberG (2013).

36 Aunque en el caso concreto se desestime la demanda porque no se acredita las deficiencias del camión: ILUSTRE MUNICIPALIDAD DEL CARMEN CONTRA CECOR S.A. (2016).

37 EAston Muebles Limitada CON AAA2K SOFTRAM COMPUTACIÓN LTDA. (2010). En relación con la identificación como consumidor de una persona física que adquiera un vehículo: FUNDACIÓN EDUCACIÓN COLEGIO MADRES DOMINICAS CON ELECTRODIESEL O LECTRO-DIESEL LTDA. (2011).
} 
En el caso del modelo beta, el momento de la entrega del bien y de la factura son diferentes.

De modo que cabe preguntarse en qué medida incide el derecho tributario sobre la garantía legal. ¿Crea de facto una tutela diferente dependiendo de si la compraventa es presencial o a distancia? Debe apuntarse que quedará fuera del análisis el límite analizado anteriormente relativo a la no suspensión del plazo para el ejercicio de la resolución (ya que puede aplicarse al modelo alfa y beta de igual manera).

Para poder sistematizar el posible panorama es oportuno realizar cuatro constataciones importantes. 1) A los efectos del tema aquí tratado la factura y la boleta reciben el mismo tratamiento, aunque el momento de su emisión difiera. 2) Con todo, la factura tiene mérito ejecutivo y no así la boleta (véase VII.D). 3) La factura es siempre electrónica independiente de que la compraventa sea presencial u online, por lo tanto, esto no incide sobre la diferenciación en la tipología de venta. En cambio, el tratamiento de la boleta es diverso, pues en la presencial podrá emitirse una manual o electrónica. 4) La obligación de emitir la boleta o factura es independiente de que el pago se haya realizado o se realice posteriormente o a plazos.

\section{B. El MOMENTO de EMISIÓN DE LA BOLETA y FACTURA Y LA NECESIDAD DE DISTINGUIR} LA CASUÍSTICA. LA CREACIÓN DE UN TERCER MODELO REMEDIAL

Aunque tanto la factura como la boleta pueden expedirse en el momento de la entrega real o simbólica, es posible que se presenten diferencias en algunos casos. Por ejemplo, en caso de compraventas online o a distancia, si la facturación puede ser posterior a la celebración del contrato ${ }^{38}$ (véase VI.C), la boleta, en cambio, puede remitirse también contextualmente con ella.

Acerca de esto último es oportuna una aclaración sobre lo que se entiende por entrega simbólica, ya que esta no debe asumirse como la tradición de muebles regulada por el art. 684 CC., sino que debe reenviarse a la norma especial del art. 17 Reglamento IVA, disposición que, si bien es parecida a la anterior, también, en parte, se aleja de ella.

Efectivamente, es importante destacar que el numeral segundo del art. 17 del Reglamento IVA la considera como simbólica "cuando dicho vendedor enajena una especie afecta al Impuesto al Valor Agregado, conservando, sin embargo, la posesión de la misma”. Esta disposición seguramente estaba pensada para un concepto de compraventa presencial (en concordancia también con el art. 1550 CC) y comporta la posibilidad de la emisión de la boleta en el momento de la celebración del contrato. Por esto la boleta presenta hoy el fenómeno de tener que emitirse en dicho momento también en caso de compraventa no presencial.

Diferente, en cambio, es el caso de la factura, puesto que dicha norma debería coordinarse con la obligación de emitirla con la indicación y fecha de la respectiva guía de despacho, al tenor del quinto inciso del art. $55^{39}$. La concordancia de estas normas conduce a que

\footnotetext{
38 Cfr. incisos primero y cuarto art. 55 Ley sobre IVA, art. 17 Reglamento IVA.

39 En este sentido debería interpretarse la frase "en esta oportunidad", del art. 55 inciso quinto de la Ley sobre IVA: "En caso que las facturas no se emitan al momento de efectuarse la entrega real o simbólica de las especies, los vendedores deberán emitir y entregar al adquirente, en esa oportunidad, una guía de despacho numerada y
} 
la facturación solo puede ser hecha en el mismo momento o después de la guía de despacho. Siendo esta última ${ }^{40}$ un documento tributario que respalda el traslado del bien y que el vendedor debe confeccionar cada vez que aquel circule, la consecuencia será que la emisión de la factura coincidente con la celebración del contrato on line o a distancia, se dará solamente en la hipótesis en que el objeto se envíe el mismo día en que se haya comprado.

En definitiva, en las compraventas no presenciales la boleta podrá generarse en el intervalo que media entre la celebración del contrato y la entrega del bien (cfr. art. 55 Ley IVA, art. 17 No 2 Reglamento IVA). Y en el caso de la factura, será entre la confección de la guía de despacho, es decir, el envío del bien y un momento incluso posterior a la entrega, es decir, hasta el décimo día del mes siguiente a la celebración del contrato, como prescribe el inciso cuarto del art. 55 Ley IVA: "los contribuyentes podrán postergar la emisión de sus facturas hasta el décimo día posterior a la terminación del período en que se hubieren realizado las operaciones" [...] "en todo caso, corresponder su fecha al período tributario en que ellas se efectuaron".

Como consecuencia de lo visto, entonces, el modelo beta se escinde en dos submodelos, uno relativo a la expedición de la boleta y otro al de la factura, modelos que, como se verá, tendrán una diferente tutela remedial: el de la compraventa presencial y dos relativos a las compraventas a distancia (un modelo alfa y dos submodelos beta).

En todos los casos del modelo beta en que deba procederse al envío del bien, el vendedor tiene de facto un margen de elección a la hora de generar la factura para su conveniencia tributaria y su praxis empresarial y contable. En cambio, dicho margen de acción no se produce en el modelo alfa, puesto que la emisión debe realizarse contextualmente a la entrega, al tenor del art. 55.

La flexibilidad de la facturación debe coordinarse también con el art. 9 de la Ley IVA. Efectivamente, lo que es relevante para el vendedor no es tanto expedir la factura al comprador, sino identificar el momento en que le beneficie hacerlo. En este sentido, entra en juego el art. 9 Ley $\mathrm{IVA}^{41}$, por el cual se devenga la obligación de pagar el importe del IVA en la fecha de emisión de la factura o boleta.

Los diferentes momentos en que se deben generar las boletas o facturas requieren un análisis profundo y por separado de los dos submodelos beta, que, de hecho, dan lugar a tres situaciones diversas.

timbrada por el Servicio de Impuestos Internos. Esta guía deberá contener todas las especificaciones que señale el Reglamento. En la factura que se otorgue posteriormente deberá indicarse el número y fecha de la guía o guías respectivas" (destacado añadido).

40 Véase art. 55 Ley sobre IVA y art. 70 de su reglamento. Sobre varios aspectos relacionados a la guía de despacho véase Circular SII No 103 (14 de noviembre de 1979); Circular SII No 62 (28 de agosto de 1980); ReSOLUCIÓN EXENTA SII No 51 (10 de junio de 2015) que agrega en los requisitos a indicar en la guía la indicación "Patente del vehículo destinado al transporte de carga, en el que se realizará el traslado de los bienes corporales muebles, sea que la operación constituya o no venta”; RESOLUCIÓN EXENTA SII No 52 (10 de junio de 2015) que agrega la indicación de la "Patente del vehículo en el que se está cargando el combustible"; y la RESOLUCIÓN EXENTA SII No 66 (31 de julio de 2015) que aplaza de un año la entrada en vigor de la Resolución No 51.

41 En sentido similar, véase también el art. 15 Reglamento sobre IVA. 


\section{Segunda Constatación: la compraventa a distancia limita la libre elección} DE LOS REMEDIOS REVELANDO SU JERARQUÍA

Antes de todo, debe asumirse una macro comparación entre el modelo alfa y el modelo beta, para demostrar los supuestos de fluctuación entre la emisión de la boleta y la factura. Para ello se pondrá como ejemplo una compraventa de un bien mueble hecha el 2 de marzo de 2019.

En el modelo alfa, que esencialmente se identifica con las compraventas presenciales, el momento de entrega y la emisión de la boleta o factura coinciden. Por lo tanto, los tres remedios contractuales -reparación, sustitución y devolución de lo pagado- podrán ejercerse a partir del mismo día ${ }^{42}$ en un plazo de tres meses, es decir, hasta el 2 de junio.

Para realizar una comparativa con el modelo beta, que se identifica con las compraventas online o a distancia, el bien podría entregarse en una fecha posterior al contrato, por ejemplo el 23 de marzo, habiendo sido enviado el día 4. Además, es posible que la factura haya sido generada incluso después, es decir, a partir del 24 de marzo.

Asumiendo los razonamientos efectuados, en el caso de la boleta, esta podría extenderse desde el mismo 2 de marzo (cfr. art. 17 No 2 Reglamento IVA), hasta el día de la entrega. En cambio, la factura podría emitirse desde el día 4 -momento de la emisión de la guía de despacho- hasta el 10 de abril (cfr. art. 55, inciso cuarto), pero figurando su expedición en el periodo tributario correspondiente, es decir, hasta el último día del mes de marzo.

La consecuencia de esta comparativa es que, si en el modelo alfa siempre habrá elección de remedios, en la compraventa de beta no. Como puede observarse en esta última, el cómputo del plazo de su ejercicio no coincide con el de la compraventa presencial (modelo alfa). De esta forma, en el modelo beta no siempre se podrían escoger los remedios, pues, en algunos casos, el plazo para ejercerlos ya habrá expirado. Esto, a pesar de que la normativa hable de una libre opción, según el inciso $1^{\circ}$ del artículo 20 , generándose una jerarquía forzosa, derivada de las posibilidades que existen para ejercerlos. Si en principio el consumidor podría escoger entre los tres remedios, posteriormente esta facultad quedará restringida, ya sea porque no se puede impetrar la resolución del contrato, pero sí la reparación o sustitución del bien, o viceversa.

Se comparará el modelo alfa (donde el plazo de ejercicio para los tres remedios es igual) con el modelo beta. Este último contiene dos submodelos, uno relativo a las facturas (con dos supuestos: factura No 1 y factura No 2) y otro relativo a las boletas (boleta No $1 \mathrm{y}$ boleta No 2). En total se analizará, en los siguientes epígrafes, las cuatro hipótesis del modelo beta, reflejadas en la siguiente tabla.

\footnotetext{
42 Cabe recordar que, en estos ejemplos, se está asumiendo que se aplican los otros límites que se han visto: por un lado, no se suspende el plazo por una garantía convencional; o si se suspende, valdrá también en caso de devolución de la cantidad pagada según una interpretación favorable para el consumidor, de acuerdo con la visión jurisprudencial analizada anteriormente (véase arriba II.A).
} 
FERRANTE, Alfredo — "La jerarquía de remedios en la compraventa de consumo a partir de sus límites civiles y tributarios"

\begin{tabular}{|c|c|c|c|c|c|}
\hline $\begin{array}{c}\text { uo!jn!!!nsns o uọ! } \\
\text {-елеdəљ se!̣ uә oze|d }\end{array}$ & สู & สู & б & ส้ & $\bar{\sigma}$ \\
\hline $\begin{array}{c}\text { (uọ! } \\
\text {-nןosəy) sẹp uə oze }\left.\right|_{d}\end{array}$ & ส้ & ब & $\infty$ & $N$ & 6 \\
\hline seıp uə oze dd $_{\mathrm{d}}$ & ส้ & ब & $\infty$ & 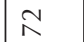 & 6 \\
\hline 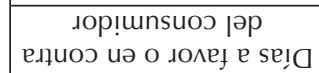 & 0 & $a$ & q & ঙ & i্ \\
\hline uọ) & $\begin{array}{l}\text { o } \\
\text { dे } \\
\grave{1} \\
\tilde{\delta}\end{array}$ & 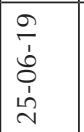 & 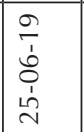 & 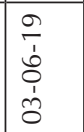 & 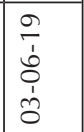 \\
\hline 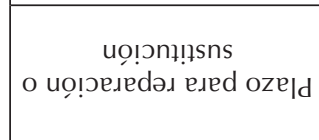 & 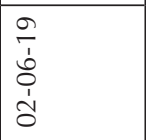 & 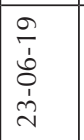 & $\begin{array}{l}\sigma \\
\frac{\sigma}{1} \\
\hat{0} \\
\hat{1} \\
0\end{array}$ & 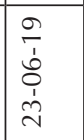 & $\begin{array}{l}a \\
\frac{1}{1} \\
\hat{0} \\
\hat{1} \\
\hat{0}\end{array}$ \\
\hline 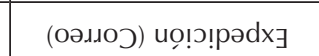 & 0 & $\stackrel{9}{2}$ & i & $\sigma$ & in \\
\hline 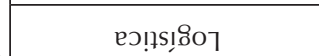 & 0 & N & N & 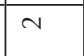 & N \\
\hline 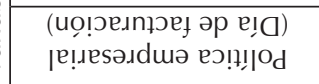 & 0 & $\bar{\sim}$ & $\bar{v}$ & 0 & 0 \\
\hline 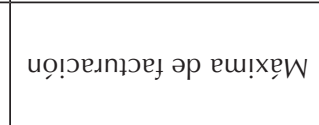 & & $\begin{array}{l}\sigma \\
\frac{\sigma}{1} \\
\dot{1} \\
\dot{1}\end{array}$ & 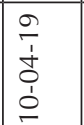 & $\begin{array}{l}\frac{\sigma}{\overline{1}} \\
\hat{0} \\
\hat{\omega} \\
\tilde{v}\end{array}$ & $\begin{array}{l}\sigma \\
\frac{a}{d} \\
0 \\
\dot{1} \\
\delta\end{array}$ \\
\hline 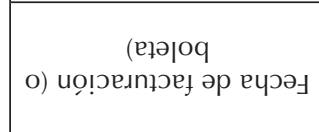 & $\begin{array}{l}\frac{\sigma}{c} \\
\tilde{0} \\
\grave{0} \\
\delta\end{array}$ & $\begin{array}{l}\frac{a}{c} \\
\hat{\tilde{O}} \\
\dot{\omega} \\
\tilde{\omega}\end{array}$ & $\begin{array}{l}\frac{a}{c} \\
\tilde{o} \\
\dot{1} \\
\sim\end{array}$ & $\begin{array}{l}\frac{\sigma}{c} \\
\hat{o} \\
\hat{0} \\
\tilde{\theta}\end{array}$ & $\begin{array}{l}\frac{\sigma}{1} \\
\tilde{O} \\
\tilde{O} \\
\tilde{\sigma}\end{array}$ \\
\hline оu!̣sәр в ере8ə|า & 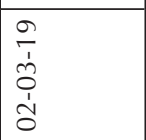 & $\begin{array}{l}\sigma \\
\tilde{c} \\
\hat{n} \\
\dot{1} \\
\tilde{v}\end{array}$ & $\begin{array}{l}0 \\
\frac{1}{j} \\
\dot{d} \\
\dot{1} \\
0\end{array}$ & $\begin{array}{l}0 \\
\bar{n} \\
\tilde{n} \\
\dot{v} \\
\tilde{v}\end{array}$ & $\begin{array}{l}0 \\
\frac{1}{1} \\
\dot{d} \\
1 \\
\tilde{0}\end{array}$ \\
\hline 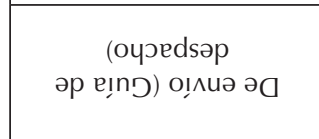 & $\begin{array}{l}\text { ô. } \\
\tilde{0} \\
\grave{1} \\
\tilde{0}\end{array}$ & $\begin{array}{l}\frac{a}{5} \\
\tilde{0} \\
+ \\
0\end{array}$ & $\begin{array}{l}\frac{a}{1} \\
\tilde{o} \\
\dot{1} \\
\dot{0}\end{array}$ & $\begin{array}{l}0 \\
\frac{0}{1} \\
\tilde{o} \\
\dot{1} \\
\dot{1}\end{array}$ & $\begin{array}{l}0 \\
\frac{0}{1} \\
\tilde{O} \\
\dot{1} \\
\dot{0}\end{array}$ \\
\hline оఘ & $\begin{array}{l}\sigma \\
\frac{\sigma}{1} \\
\tilde{1} \\
\dot{1} \\
\tilde{0}\end{array}$ & $\begin{array}{l}\sigma \\
\tilde{\sigma} \\
\tilde{n} \\
\dot{1} \\
\tilde{0}\end{array}$ & $\begin{array}{l}\sigma \\
\\
\tilde{n} \\
\stackrel{1}{1} \\
\tilde{0}\end{array}$ & 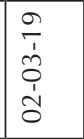 & \begin{tabular}{|c|c}
0 \\
$\tilde{1}$ \\
$\tilde{o}$ \\
1 \\
$\tilde{1}$ \\
\end{tabular} \\
\hline נ̊ & 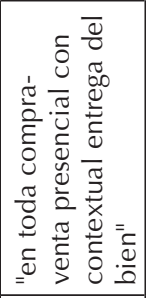 & 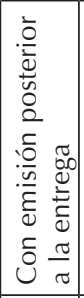 & 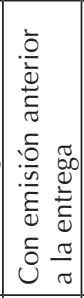 & 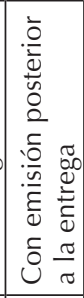 & 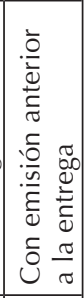 \\
\hline & & 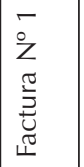 & 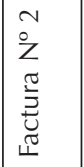 & $\mid \begin{array}{l}- \\
0 \\
z \\
\frac{\pi}{0} \\
0 \\
0\end{array}$ & $\begin{array}{l}N \\
0 \\
Z \\
\widetilde{J} \\
\frac{\pi}{0} \\
0\end{array}$ \\
\hline & Eyl & \multicolumn{4}{|c|}{ Еұәg } \\
\hline
\end{tabular}


El gráfico comparativo siguiente (tabla 1) demuestra la macro diferencia existente entre compraventas presenciales y a distancia. El análisis de los varios casos se realizará en los siguientes epígrafes, ya que es necesario ir más allá y valorar si es el sistema de libre elección o el de jerarquía el que beneficia el consumidor.

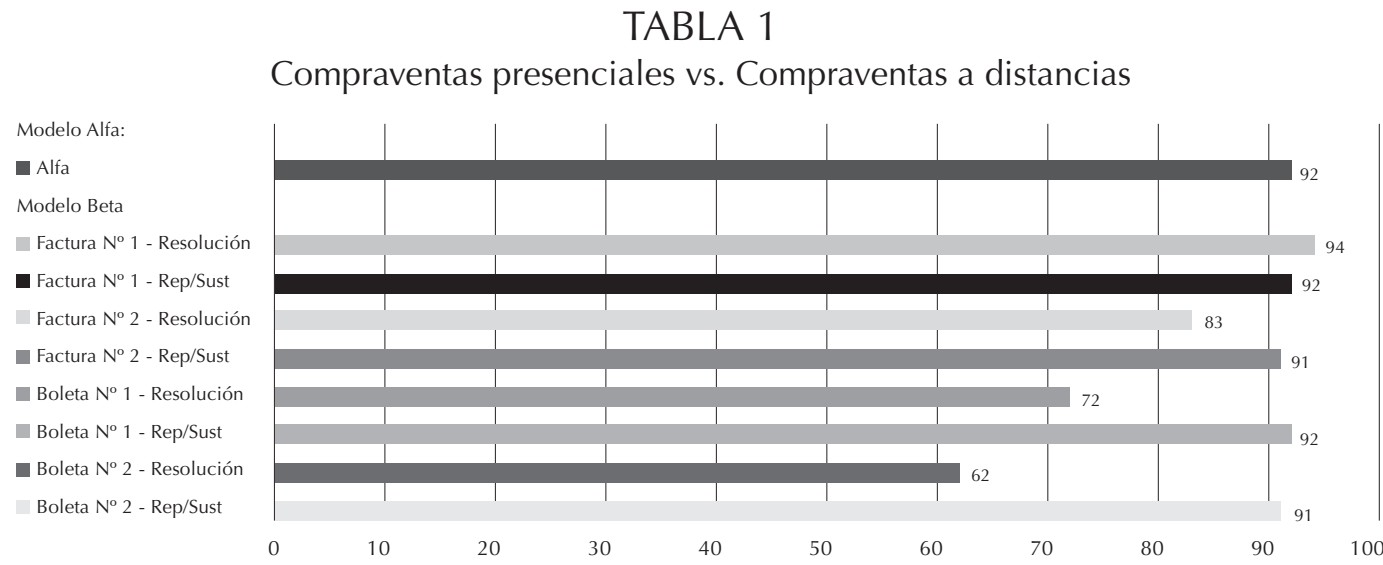

Los números que están a la derecha de cada banda marcan el día de efectiva posesión material del bien (véase más abajo VII.D).

\section{MODELO DE LIBRE ELECCIÓN O MODELO JERÁRQUICO: ¿CUÁL ES EL MÁS BENEFICIOSO?}

Frente a la pregunta acerca de si es el modelo de venta presencial (modelo alfa) o el modelo de compraventa a distancia (modelo beta) el que beneficia más al consumidor, la respuesta al interrogante planeado es: depende.

Para realizar este examen deben considerarse tres variables del modelo beta que podrían incidir sobre la tutela efectiva del consumidor: 1) la logística, es decir, el mayor o menor periodo de tiempo en despachar el envío; 2) la expedición, que es el espacio temporal en el que tarda en llegar el bien desde su envío; y 3) la política empresarial, relacionada con la flexibilidad para emitir la boleta o factura.

Fijados estos parámetros se analizarán tanto respecto de la emisión de la factura (VII. A) como de la boleta (VII.B) y se observará como inciden 1) sobre la interacción de los tres remedios a disposición del comprador; 2) específicamente sobre la resolución del contrato; 3) en la comparación entre los submodelos beta y la compraventa presencial.

\section{A. Factura y Remedios CONTRACtUales}

Para estudiar la interacción de los tres remedios que benefician al consumidor en caso de que se emitan facturas, deben formularse dos ejemplos, mezclando la flexibilidad de su emisión o "política empresarial", con la "expedición", es decir, el periodo de llegada del bien. La tercera variable, aquella relativa a la "logística", no será relevante, ya que la fecha de envío seguirá el contexto de cada hipótesis de este modelo. 
Retomando el caso planteado, es decir, un contrato celebrado el 2 de marzo, con emisión de la guía de despacho el día 4 y factura de 25 de marzo, se analizarán los dos ejemplos.

En el primero (denominado "factura No 1"), se agregará el hecho de que la llegada del bien se verifique antes de la emisión de la factura, como podría ser el 23 marzo. En el segundo ejemplo (denominado "factura No 2"), se supondrá que la emisión de la factura sea en un momento posterior, el 3 de abril.

A continuación, se revisarán las diferencias y las consecuencias de la operatividad de las variables.

\section{A.1. Con respecto a la jerarquía remedial}

Como ya se ha evidenciado (véase arriba IV.C) la situación que se presenta es de una jerarquía remedial; sin embargo, dependiendo del momento de la emisión de la factura en relación con la llegada del bien, esta puede invertirse.

Efectivamente, en el caso del primer ejemplo ("factura No 1") el hecho de recibir el bien antes de la emisión de la factura hará que el plazo para pedir la devolución de la cantidad pagada sea mayor que aquel de solicitud de reparación o sustitución: si para la primera se podrá hasta el 25 de junio, respecto de los demás remedios será solo hasta el 23 del mismo mes.

Todo lo contrario se verifica cuando la emisión de la factura es anterior a la recepción del bien, puesto que, como indica el segundo ejemplo ("factura No 2"), el consumidor podrá demandar la reparación y sustitución hasta el 3 de julio, en circunstancias que en la resolución solo tendrá plazo hasta el día 25 del mes anterior.

Como puede verse, se presenta un modelo con una jerarquía que podría definirse "fluctuante" y que depende de la rapidez de la entrega y de la voluntad de emitir la factura.

TABLA 2

Factura y Jerarquía remedial

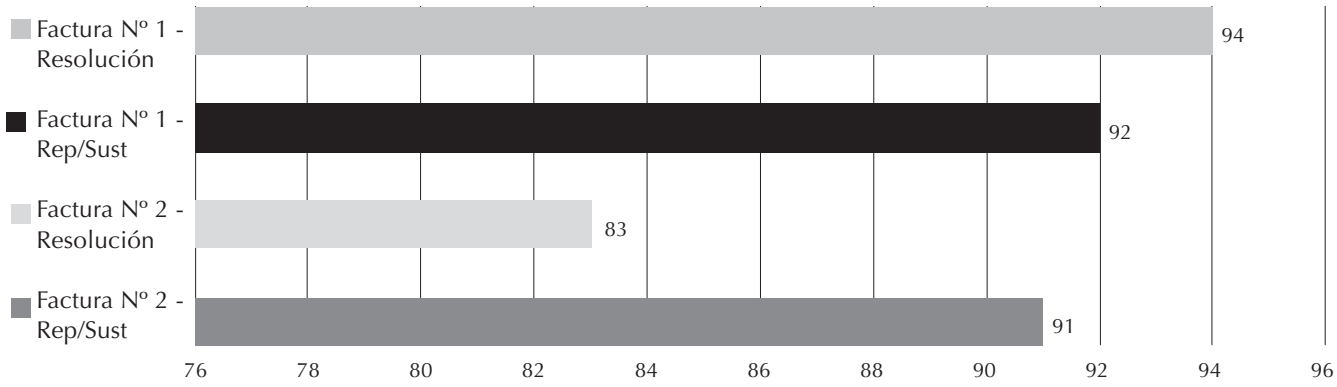

En esta tabla 2, los números que están a la derecha de cada banda marcan el día de efectiva posesión material del bien, situación que vuelve a incidir sobre el modelo, en lo que respecta a la resolución del contrato, dependiendo, como se verá a continuación, de si se trata de factura (VII.A.2) o boleta (VII.B.2) y también de acuerdo con el momento de adquisición del bien (VII.D). 


\section{A.2. Con respecto a la resolución del contrato}

Si se analizan en términos abstractos los dos casos, parecieran no existir diferencias ya que, tanto en la "factura No 1" como en la "factura No 2", el comprador tiene exactamente el mismo periodo para solicitar la resolución, esto es, hasta el 25 de junio.

En general, el ejercicio de la resolución será poco ventajoso para el consumidor si la factura se genera antes de la recepción del bien, dado que el plazo se computará antes de que el objeto haya llegado a su poder. Con todo, puede presentarse un modelo más beneficioso si se ha emitido la factura después de la recepción del bien ("factura No 1"), por cuanto, aunque en rigor el plazo de ejercicio es el mismo, el comprador habrá tenido la posesión material del bien por un periodo más largo.

En este sentido, mientras más rápida sea la entrega del bien (variable "expedición"), más tiempo lo tendrá para comprobar si tuviese alguna disconformidad.

TABLA 3

Factura y resolución del contrato

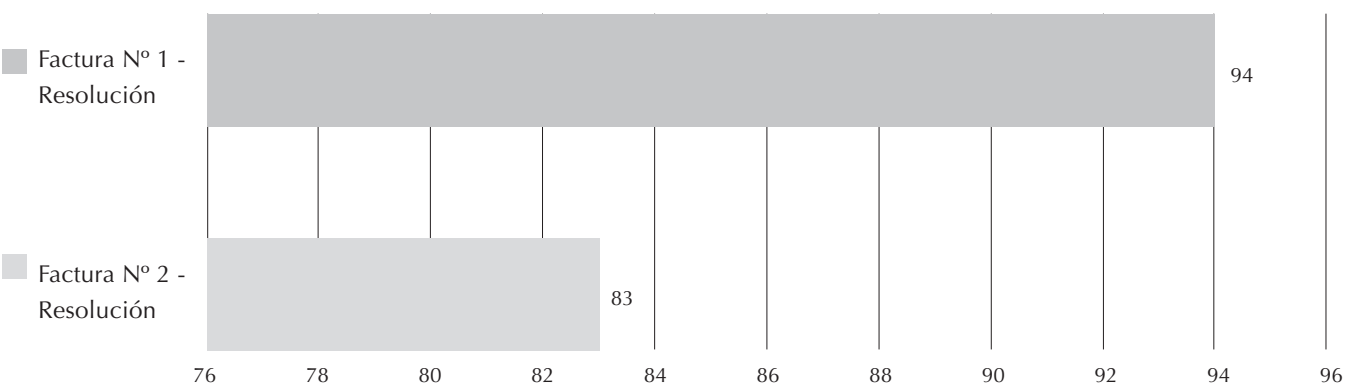

Efectivamente, como se observa en el gráfico, el caso en que se haya facturado posteriormente el consumidor tendrá 11 días más de posesión material (se resta 94-83). Este rango será más o menos amplio dependiendo la política empresarial y la mayor o menor celeridad en la llegada del producto.

\section{A.3. Con respecto a la compraventa presencial}

Asumido que el modelo de compraventa presencial da lugar a la libre elección y la que es a distancia a una jerarquía de remedios, debe revisarse cuál podría ser más favorable para el consumidor. Para ello, deberán compararse los ejemplos formulados en el modelo de la compraventa presencial (más bien del modelo alfa), donde el contrato, la entrega y emisión de la factura se han concretado el día 2 de marzo.

En definitiva, al contratar presencialmente, se presentará la ventaja de la libre elección de los remedios, pero con un plazo de ejercicio menos beneficioso para la resolución cuando la factura se emita después de la entrega, más aún si se ha verificado una rápida expedición. 
TABLA 4

Compraventas presenciales vs. Compraventas a distancias (Facturas)

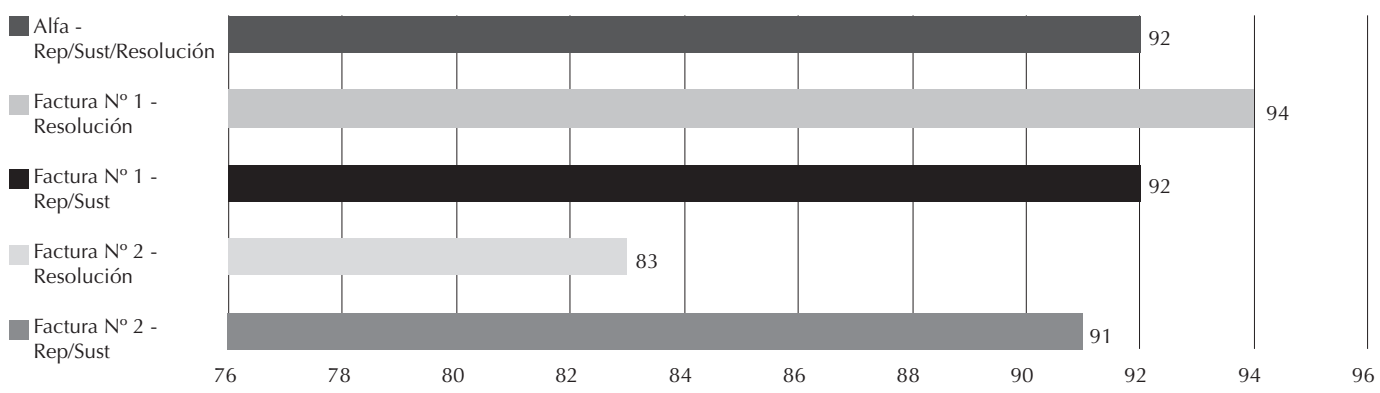

\section{B. BOLETA Y REMEDIOS CONTRACTUALES}

De acuerdo con lo señalado, en el caso de las compraventas a distancia, el margen de tiempo para la emisión de la factura será muy flexible, comprendiendo un periodo de tiempo que va desde la celebración del contrato hasta la recepción del bien.

\section{B.1. Con respecto a la jerarquía remedial}

La primera constatación que debe realizarse es que en la boleta no es obligatoria la guía de despacho y que, en la práctica, se emite lo más pronto posible (véase el art. 17 No 2 reglamento IVA). Por lo tanto, la gran diferencia respecto de la factura es que ella se puede generar también durante el periodo que va entre la celebración del contrato y el anterior a la guía de despacho (al margen de poder hacerse en un momento posterior).

Dado que la emisión de la boleta del modelo beta se realizará siempre antes de la entrega, la consecuencia es que, en estos casos, se dará lugar a un prototipo que, si bien es jerárquico, prevé una única tipología: aquella en que el plazo para ejercer la reparación y sustitución será más amplio que el de la resolución.

Comparando los modelos "boleta No 1" y "boleta No 2" que corresponden a los casos antes delineados, si la emisión es el día 3 de marzo se comprobará que en ambos el plazo para ejercer la resolución será el 2 de junio, mientras que los demás remedios se podrán deducir hasta los días 23 de junio ("boleta No 1") o 3 de julio ("boleta No 2"), respectivamente.

Por lo tanto, en estas hipótesis habrá un único modelo jerárquico que dependerá solo de la variable "elección empresarial", todas las veces en que se emita la boleta antes de la guía de despacho. En cambio, no influiría, dentro de las varias hipótesis de boleta, la "logística”, por los mismos razonamientos efectuados en el caso de emisión de factura (véase arriba VII.A).

Esencialmente, este modelo coincidirá con el modelo "Factura No 2", ya que, si bien se podría expedir la boleta después de la guía de despacho, esto solo sería posible hasta entrega del bien, y no en un momento posterior (que correspondería, mutatis mutandis, al modelo "Factura No 1"). En consecuencia, el modelo jerárquico que se daría en caso de boleta será exclusivamente aquel en que el consumidor tiene más tiempo para solicitar la reparación o sustitución del bien. 
TABLA 5

Boleta y jerarquía remedial

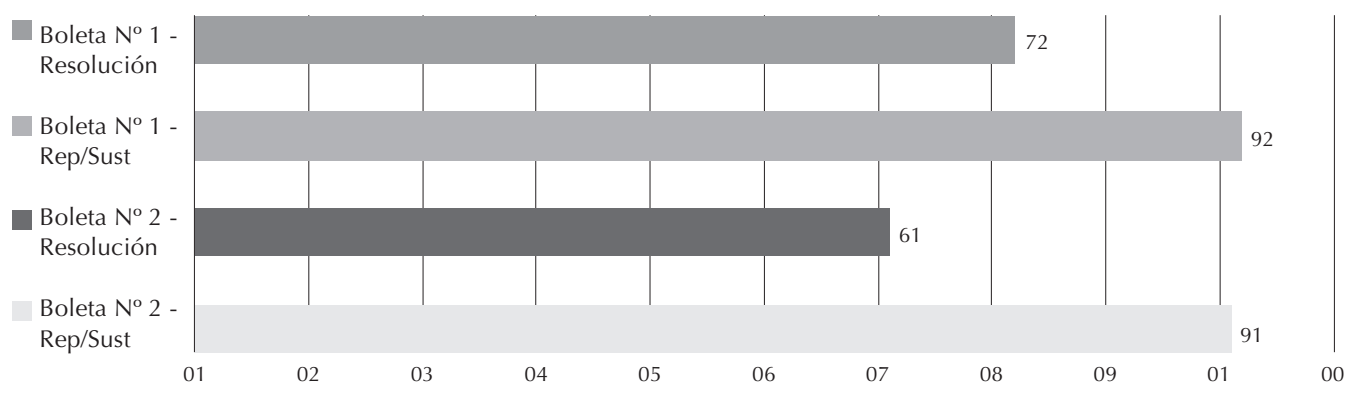

\section{B.2. Con respecto a la resolución del contrato}

Si se examina solo la variable "expedición", podrá evidenciarse que, mientras más rápida sea la entrega, más eficiente será el remedio de la resolución. Sin embargo, al margen de lo analizado, podrá verse que, en todos estos casos, el modelo será menos beneficioso para el comprador, en el sentido que empezará a correr el plazo sin que tenga la posesión material el bien; a diferencia de lo que ocurre con la factura cuando ella se genera después de la entrega del bien.

\begin{tabular}{|c|c|c|c|c|}
\hline & & & Plazo para reparación o sustitución & Plazo para resolución \\
\hline \multirow{5}{*}{$\begin{array}{l}\frac{0}{0} \\
\frac{0}{0} \\
\frac{0}{2}\end{array}$} & Alfa & & $02-06-19$ & 02-06-19 \\
\hline & \multirow[t]{4}{*}{ Beta } & Factura $\mathrm{N}^{\circ} 1$ & $23-06-19$ & $25-06-19$ \\
\hline & & Factura $\mathrm{N}^{\circ} 2$ & 03-07-19 & 25-06-19 \\
\hline & & Boleta $\mathrm{N}^{\circ}$ & $23-06-19$ & 03-06-19 \\
\hline & & Boleta № & 03-07-19 & $03-06-19$ \\
\hline
\end{tabular}

\section{TABLA 6}

Boleta y resolución de contrato

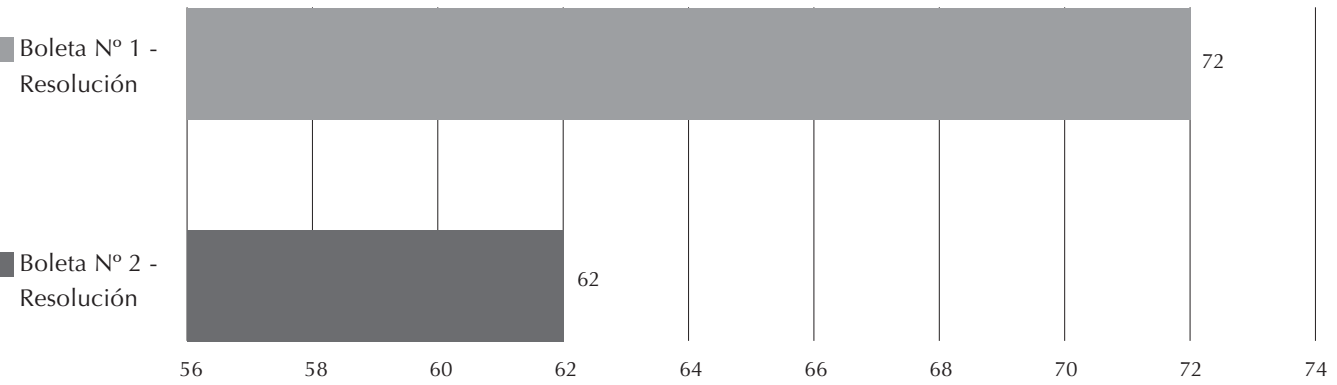

\section{B.3. Con respecto a la compraventa presencial}

En este punto, dado que los razonamientos son los mismos que en caso de la emisión de la factura, se hace un reenvío a lo señalado en su oportunidad. 
En general, aunque el modelo beta se caracteriza por una jerarquía de remedios, no necesariamente esta es más perjudicial que el modelo alfa, ya que, en determinados casos puede ser más beneficioso si lo que se quiere es pedir la resolución del contrato. Efectivamente, en el modelo beta existen algunas posibilidades de adquirir materialmente el bien por un periodo más largo, debido al margen de elección sobre la emisión de boleta o factura. Solo en aquellas situaciones en que el plazo se computa a pesar de que el consumidor no tenga esta posesión, el modelo sería ineficiente, prefiriéndose la compraventa presencial (modelo alfa).

TABLA 7

Compraventas presenciales vs. Compraventas a distancias (Boletas)
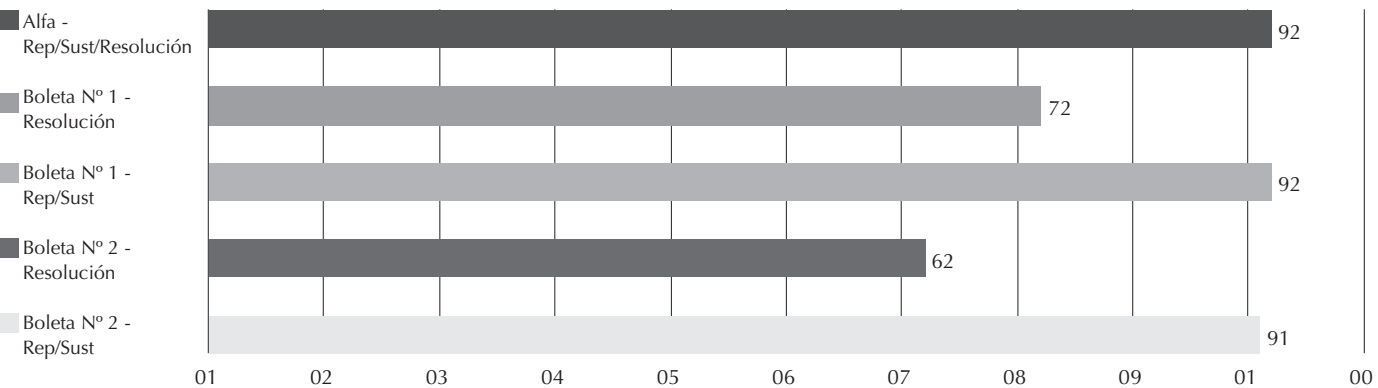

C. Tercera constatación: Boleta vs. Factura

De una breve comparativa, la compraventa con boleta resulta tener una tutela menos efectiva para el comprador. Por un lado, esta no tiene los márgenes beneficiosos que pueden tener las hipótesis en que la factura se gestione luego de la entrega del bien sobre la resolución. Por otro, la jerarquía siempre favorecerá la acción de reparación y sustitución.

En este caso, la variable relativa a la "logística" debe entrar en juego, comparando estos dos submodelos. Por lo mismo, debe valorarse si la emisión anterior o posterior a la guía de despacho comporta una diferencia para la tutela del consumidor.

Claramente cada día que se retrase dicha emisión respecto de la boleta ya expedida significaría mermar las posibilidades de pedir la resolución frente a los demás remedios (en comparación con el mismo modelo relativo a la emisión de la factura). En este sentido, si por la "libertad empresarial" se decidiera emitir la boleta cuanto antes y hacer un envío tardío, la tutela del consumidor se soslayaría, fortaleciendo la jerarquía y ampliando los plazos de ejercicio para la reparación y sustitución.

Por este motivo, debería asumir relevancia la variable de la "logística", pues influye con la de la "política empresarial" cuando la boleta es anterior a la guía de despacho. En efecto, en comparación con el modelo de la factura, los plazos para demandar la reparación y sustitución se vuelven divergentes respecto a los de la resolución. 
TABLA 8

Boletas vs. Facturas
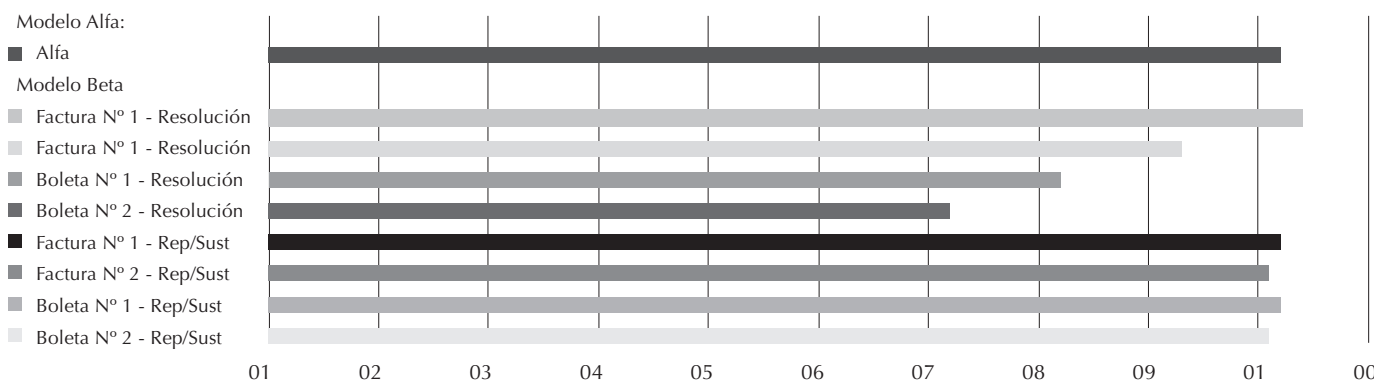

En definitiva, al hecho de que el modelo de la factura parezca ser más favorable que el recientemente descrito, se añade un gravísimo inconveniente: en la práctica, dado que la relación es esencialmente con una persona que no hace utilización mixta del bien, la mayoría del tráfico se realizan mediante la emisión de la boleta y no de facturas. Esto evidencia la poca preocupación del legislador por la efectiva protección del consumidor.

\section{D. ¿PUEDE EL COMPORTAMIENTO DEL CONSUMIDOR INFLUIR EN LA APLICACIÓN DEL SISTEMA REMEDIAL?}

Los dos submodelos beta corresponden a una jerarquía remedial que queda influenciada por algunas variables. La pregunta necesaria es si el consumidor puede influir sobre ellas.

Se ha visto que en caso de emisión de factura las variables a considerar son la rapidez y la llegada del bien (expedición). Un menor tiempo de retención beneficia al consumidor ya que 1) reduce la divergencia de los plazos de ejercicio entre reparación, sustitución y resolución 2) en el modelo de facturas expedidas después de la entrega, el consumidor tiene la posesión material previa y puede comprobar la disconformidad con mayor holgura de tiempo.

Efectivamente, si se tuviera conocimiento de estas diferencias, el comprador podría elegir un courier más rápido para servirse de lo afirmado. No obstante, los courier exprés suelen cobrarse a un precio más caro ¿por qué este coste debe ser asumido por el consumidor si se trata de un caso de tutela legalmente establecido? ${ }^{43}$

Ya que se trata de una garantía "legal", predispuesta expresamente por los arts. 19 y ss., la optimización y efectividad de las facultades que prevé no deberían quedar sujetas a este tipo de contingencias que no dependen de su beneficiario. En definitiva, si bien este parámetro podría ser controlable por el consumidor, lo sería solamente a un coste económico que no debería tener que asumir.

\footnotetext{
43 Aunque es claro -como ya se ha sostenido, entre otros, por Pinochet (2013B) p. 376- que en este ámbito debería primar el principio pro consumidor, aplicándosele la solución menos gravosa, la realidad hace constatar que, en determinados casos, esto encuentra difícil concreción. Aunque en línea teórica quiera aplicarse una interpretación favorable para el consumidor; es él quien debe asumir dicho gasto, no pudiéndolo desgravar directa e inmediatamente de la contraparte. En este sentido, el principio pro consumidor no resulta efectivo en la realidad cotidiana, aunque en un eventual juicio que interprete la relación contractual el juez sea proclive a aplicarlo.
} 
Menos controlable sería la variable de la "política empresarial", ya que es la propia entidad la que decide una expedición de la boleta o factura más o menos inmediata, en relación con la entrega del bien. En parte, se presenta una condición meramente potestativa, que altera los valores que subyacen a la libre elección de la garantía legal.

Ahora bien, los efectos de estas políticas empresariales podrían reducirse en los casos en que se emita la factura. Se ha dicho que esta puede postergarse "hasta el décimo día posterior a la terminación del período en que se hubieren realizado las operaciones", debiendo "en todo caso, corresponder su fecha al período tributario en que ellas se efectuaron" (art. 55 Ley IVA). Este aspecto significa que, aunque la factura se genere al mes siguiente, deberá indicar el periodo tributario respectivo, es decir, en los ejemplos formulados hasta ahora, podría emitirse hasta el 10 de julio, pero debería indicar como máximo el 30 de junio.

En términos generales, hay también que considerar que las empresas podrían tener interés en una emisión rápida de la factura dado que la ley de facturas les otorga mérito ejecutivo $^{44}$. Poco influenciaría, en cambio, el momento del pago frente al SII ${ }^{45}$.

Si es así, el comportamiento del consumidor, en parte, podría influir sobre la emisión de la factura solo mediante un cuarto parámetro, el "momento de adquisición". Efectivamente, todas las compraventas realizadas hacia el final de cada mes son más proclives a tener una rápida facturación. Además, seguramente esta tendrá una fecha posterior a la entrega (considerando que en determinados casos la fecha debe ser la de junio). Por esto puede concluirse que una compraventa realizada los primeros días del mes podría ser más ventajosa, por lo menos estadísticamente, que una compraventa realizada a final de mes.

Ahora bien, la decisión del momento de compra por parte del consumidor influye también de otra manera sobre el sistema remedial. Esto se debe a que el plazo para ejercer la garantía legal en caso de venta de bien durable está computado en meses y no en días. Como consecuencia, surge una diferencia con el sistema remedial de bienes perecibles (véase más abajo VIII) y con los contratos de servicios, en los que sus plazos son de 7 y 30 días, respectivamente.

El hecho de haberse remitido a meses y no a días, en el primer caso, hace que la adquisición se vuelva más beneficiosa en los meses con mayor duración. Por lo tanto, comprar en febrero sería más inconveniente que comprar en marzo, sobre todo en el prototipo de "factura No 2". Esto se puede constatar claramente en los gráficos anteriores y que pude verse cómo, incluso, los días superan los 90. Así que, si el mes de facturación corresponde a 30 días, este factor no es el mismo respecto de la aplicación de la garantía legal.

Un claro ejemplo se desprende de los días de efectiva posesión del bien, que cambian dependiendo del mes de referencia. Por ello, a pesar de que exista un mismo plazo de ejercicio (3 meses), los días para ejercer la resolución cambian: haber recibido materialmente el bien en marzo o abril es distinto, puesto que el primer mes tiene un día más. Por tanto, será más beneficioso comprar después de febrero para no incluir este mes de corta duración

\footnotetext{
44 Véase el art. 9 Ley No 19.983, de 2004.

45 Con carácter mensual, el emisor de la factura debe pagar al Estado el importe correspondiente al IVA mediante la presentación del formulario 29 que debe presentarse hasta el día 12 del mes siguiente al periodo tributario que se desase declarar. Y en caso de facturación electrónica, hasta el día 20: véase Consulta SII, Identificador 001.030.1060.008 (24 de octubre de 2018).
} 
en el cómputo. Más ventajoso será comprar en un mes que tiene 31 días (así se computarán, dentro de los tres meses, dos de 31 días) o en junio o diciembre, en que los dos meses siguientes tienen 31 días (julio-agosto y diciembre-enero).

Este problema no se plantaría si el plazo se hubiera computado en días.

\section{E. ¿HAY OTROS DOCUMENTOS EQUIVALENTES A LA BOLETA O FACTURA?}

Otro aspecto importante para valorar, es si la emisión de otros documentos se computa igual que la boleta o factura para pedir la resolución del contrato, a tenor del art. 21. En este sentido, debe hacerse particular referencia a dos de ellos: A) el recibo de pago o comprobante y B) la guía de despacho.

A) El interrogante en relación con el recibo de pago se justifica, ya que en determinadas circunstancias - pago con tarjeta de crédito o débito- reemplazaría la emisión de la boleta o factura. Efectivamente, por lo dispuesto en una resolución del SII del año $2015^{46}$, estos documentos pueden obviarse si el pago se efectúa integralmente mediante un terminal POS $^{47}$. Pero este problema no se daría en los contratos de consumo, caracterizados por la relación business to consumer, puesto que en estos casos la entrega del comprobante de pago no puede reemplazar la emisión de la boleta electrónica ${ }^{48}$.

B) En relación con la factura, debería analizarse si respecto de la devolución de la cantidad pagada, la guía de despacho podría considerarse como sustituto de determinación de fecha. El interrogante surge porque la factura debe indicar también la data de la respectiva guía de despacho. Aunque la normativa relativa a esta última sea meramente administrativa, indirectamente podría incidir sobre los plazos de ejercicio de la garantía legal y sobre la tutela efectiva del consumidor, todas las veces que se emita en reemplazo de la factura.

Ahora bien, si se expiden tanto la guía de despacho como la factura, ¿cuál sería la fecha que inicia la contabilización del plazo en relación con la resolución del contrato? Aquí pueden plantearse dos interpretaciones que generan dos submodelos.

\footnotetext{
46 Resolución eXenta SII No 5 (22 de enero de 2015), que establece normas en relación a la emisión del comprobante o "recibo de pago" de transacciones pagadas a través de medios electrónicos, como sustituto de la boleta de venta y servicios, de acuerdo con lo dispuesto por el art. 54 del D.L No. 825 de 1974.

47 Salvo que se pague en parte en efectivo y en parte con tarjeta, caso en el cual debería necesariamente emitirse boleta o factura. Punto No 3 Resolución EXENTA SII No 5 (22 de enero de 2015).

48 Esto se deduce por la primera parte del punto No 7 de la resolución, que afirma: "De acuerdo al Artículo 54 del D.L. No 825, de 1974, los contribuyentes emisores de Boletas Electrónicas, autorizados según lo indicado por la Resolución exenta SII No 19, de 2008, al recibir un pago realizado por medio electrónico en ventas efectuadas o servicios prestados a consumidores finales, deberán continuar emitiendo dichos documentos tributarios, no siéndoles aplicable el reemplazo de la emisión de la Boleta Electrónica por la entrega del comprobante de pago": véase la ReSOlUCión EXENTA SII No 5 (22 de enero de 2015). Aquí es útil anotar que se admitía solo la documentación original de factura o boletas: SERNAC contra COMERCIAL ECCSA S.A. (2017). La doctrina, en cambio, se ha decantado por una interpretación más amplia: cfr. NASSER (2013) p. 552.
} 
Si se asumiera que cuenta la fecha de la factura, los casos ya se analizaron anteriormente. Si, en cambio, la fecha fuera la de la guía de despacho, el cómputo del plazo siempre será anterior a la entrega del bien y, por lo tanto, esta casuística será equivalente al modelo "factura No 2".

La primera postura se basaría en una interpretación literal del art. 21 que señala a la "factura o boleta". Además, efectivamente, la Ley de IVA y su art. 55 tienen efectos meramente administrativos y otras finalidades: la contable y de seguridad a la hora de comprobar el tránsito de un bien en carretera.

La segunda postura, que defiende que el plazo se cuente desde la guía de despacho, haría prevalecer una interpretación sistemática entre el art. 21 Ley 19.496 y el art. 55 Ley IVA. Aquí, aunque la factura pueda generarse posteriormente, en su glosa debe hacerse referencia a la guía de despacho y a su fecha para la entrega del bien corporal mueble. Por lo que, siguiendo los ejemplos formulados, el día para contabilizar el término en que se puede pedir la resolución sería el 4 de marzo. Para esta interpretación no podría sostenerse que la Ley IVA tiene efectos meramente administrativos, por cuanto es el mismo art. 21 Ley 19.496 el que se remite expresamente a la norma tributaria.

Esta interpretación sistemática podría ser la más coherente, pero de facto mengua el derecho del consumidor. Se presenta una incongruencia más del sistema, ya que claramente queda fuera del supuesto analizado la posibilidad en que la guía de despacho y factura lleguen el mismo día, aspecto que a veces se verificará, pero, dicho supuesto sería parte del modelo alfa.

Un aspecto diferente a la devolución de lo pagado es la reposición del producto. Dado que el reemplazo no es oneroso, sino gratuito, esta operación solamente daría lugar a la emisión de otra guía de despacho, pero no de factura ${ }^{49}$. Con todo, dado que el ejercicio de la sustitución se computa desde la recepción del bien, este aspecto práctico no es relevante.

\section{EL PECULIAR CASO DE LAS COMPRAVENTAS DE BIENES PERECIBLES: CREACIÓN DE UN ULTERIOR MODELO REMEDIAL}

Un discurso aparte requiere la garantía legal en relación con los bienes perecibles o aquellos que por su naturaleza estén destinados a ser usados en plazos breves. En estos entra en juego lo dispuesto por el inciso sexto del art. 21, que impone como periodo para ejercer la garantía legal "el impreso en el producto o su envoltorio o, en su defecto, el término de siete días".

Dado que el inciso sexto hace referencia al primero del art. 21, este plazo se aplica tanto a los tres remedios (reparación, sustitución y resolución), como a los indicados en

\footnotetext{
49 Así se establece que "el mero reemplazo de manera gratuita hecho en virtud del deber de garantía legal, no constituye una venta, consecuentemente no procede la emisión de boleta o facturas, como tampoco notas de crédito y débito por cuando en la condición de gratuidad, no hay una modificación en el impuesto previamente fracturado. Consecuentemente para respaldar el traslado de dichos productos se deberá emitir una guía de despacho, en las que se indique expresamente que la salida del bien de inventario de la empresa es a causa del cumplimiento del deber de garantía legal o convencional": Oficio de la Subdirección nORMATIVA SII No 157 (20 de enero de 2016). En el mismo sentido, Oficio de la Subdirección normativa SII No 2919 (9 de junio de 2006).
} 
este inciso. Por lo tanto, en el caso de esta tipología de bienes no aplicarían los diferentes días de inicio de cómputo del plazo analizados anteriormente.

Sin embargo, existen algunas peculiaridades. De lo que se acaba de afirmar, debe concluirse que los bienes que se consumen en un "plazo breve" serán aquellos que materialmente tienen posibilidades de utilización inferior a los siete días, dado que el inciso sexto del art. 21 establece que, en ausencia de indicación de vencimiento, por defecto, habrá un plazo máximo de $\operatorname{siete}^{50}$. Si, en cambio, existiera una fecha preferible de consumo impresa en el producto o en el envoltorio, esta será el límite para ejercer el remedio.

La peculiaridad de la situación predispone dos hipótesis, una con un plazo de caducidad absoluto y otro relativo. Efectivamente, todas las veces que el producto tenga una fecha de vencimiento impresa, debería aplicarse esta. En cambio, el plazo de 7 días sí tendría un momento de inicio para computar el ejercicio del medio de tutela lo tiene. En este segundo caso y por la interpretación coordinada entre los incisos primero y séptimo del art. 21, el cómputo se calcula desde la entrega, en caso de reparación y sustitución, y desde la emisión de la boleta o factura, en caso de la devolución de la cantidad pagada ${ }^{51}$.

Esto ¿conduce a diferencias en la elección de los remedios dependiendo de la tipología de venta? En principio, se presentarán dos tipologías de tutela del consumidor, dependiendo de si se trata de un bien perecible sin indicación de fecha de caducidad o con esta.

En el primer caso, potencialmente existirá libertad de elección de los remedios, dado que se trata de un mismo plazo y contabilización. El término de 7 días hará que no sea influyente la variable de la "política empresarial" (emisión de factura) ni la "logística”. Aquí influirá solo la rapidez en la entrega en los casos de venta a distancia, aunque su fluctuación será mínima, ya que primará el rápido despacho y llegada al consumidor para que reciba un producto fresco.

Pero, si hay una fecha de caducidad indicada, podría darse un sistema que no prevea la libre elección de remedios en la compraventa a distancia (modelo beta), aplicándose los mismos razonamientos efectuados para los bienes durables acerca de los momentos de emisión de boleta o factura, pero con un abanico de tiempo muchísimo más limitado.

Finalmente, la alusión a los "días" y no a los "meses" haría innecesaria la referencia al mes de compra como parámetro decisivo para el consumidor, como puede serlo para los bienes durables, creando algunos inconvenientes ya vistos (véase arriba).

Por todo lo anterior, en el caso de bienes perecibles se construye un ulterior modelo que, dependiendo de las circunstancias, varía entre la libre elección o a la jerarquía de los remedios.

\footnotetext{
50 El inciso sexto del art. 21 Ley No 19.496 de 1997 recita así: "En el caso de productos perecibles o que por su naturaleza estén destinados a ser usados o consumidos en plazos breves, el término a que se refiere el inciso primero será el impreso en el producto o su envoltorio o, en su defecto, el término máximo de siete días".

51 Por cierto, en estas ventas la reparación será muy limitada, salvo que se trate de un producto que, aunque sea alimenticio, se haya comprado también por razones estéticas (como un pastel con una determinada forma). Por ello, esencialmente, la elección de los remedios variará entre la resolución del contrato o la sustitución del bien.
} 


\section{CONCLUSIONES}

La Ley 19.496 ya tiene más de dos décadas y en ningún momento sus pasadas o recientes $^{52}$ modificaciones han tenido en cuenta la progresiva modernización de un mercado que ha cambiado sus estándares y reglas de juego. Efectivamente, el ordenamiento chileno no se ha hecho cargo de la regulación apropiada de las compraventas a distancia y online.

El incremento de las negociaciones en la web y con tarjeta de crédito hace que la normativa en parte se encuentre obsoleta por estar pensada para un diferente contexto. Esto comporta trascendencias prácticas en el sistema remedial de la garantía legal.

En definitiva, aunque la ley abogue por una libre elección de remedios, en la práctica, el sistema podrá llegar a ser jerárquico dependiendo de varios factores, como la tipología del bien (durable o perecible) y variables como la rapidez en la expedición o la elección empresarial sobre el momento de emisión de la boleta o factura.

Tendencialmente, hay, respecto de los bienes durables, tres modelos (alfa y los beta, relativos a la boleta y a la factura). De estos, el más beneficioso es el menos recurrente, que se refiere a las facturas emitidas después de la entrega. Aunque es posible, la rápida emisión de la factura no abunda en la relación $b 2 c$ ya que esta esencialmente debe asociarse al uso de las boletas.

Por lo tanto, en las compraventas a distancia (modelo beta) existe la proliferación de un modelo jerárquico en el cual reparación y sustitución tienen un más amplio periodo de ejercicio, independiente de la limitación civil por la cual no se suspende el plazo para la resolución del contrato.

La compraventa presencial (modelo alfa) es más ventajosa frente al consumidor porque asegura una libre elección, aunque se ha visto que el modelo "factura No 2" permite tener más tiempo el bien y en algunos casos sería preferible contratar a distancia. El problema en ella (modelo beta), es que entran en juego variables que no domina el consumidor o que solo podría dominar asumiendo un comportamiento más oneroso (contratación courier exprés). No obstante, la deformación de una ley que computa la garantía legal en meses, permite ofrecer alguna ventana para que el actuar del consumidor y la elección del momento de compra contribuyan a una tutela más o menos amplia del sujeto.

En definitiva, se ha evidenciado un sistema que requiere una profunda reforma y la toma de conciencia de que sus remedios deben contemplar todas las variables involucradas. De lo contrario, estas operarán según criterios arbitrarios, unilaterales o no controlables por ambas partes, lo que da lugar no solo a una poco eficiente tutela del consumidor, sino que no fomenta el correcto tráfico jurídico. Frente a este camaleónico y polifacético sistema, la compraventa presencial (el modelo alfa), es la que ofrecería más certezas, por prever siempre la libre elección de los remedios y daría más claridad sobre el comportamiento de los factores y variables analizados.

Todo esto se debe también al hecho de que la Ley 19.496 al momento de su promulgación no tuvo en consideración la preponderancia que las compraventas online asumirían,

\footnotetext{
52 Esta tutela resulta más efectiva con la aprobación del aumento de plazo de garantía de 3 meses a dos años, mediante la modificación al art. 26, Ley No 19.496, operada por la Ley No 20.081 de 2018.
} 
ni siquiera sus modificaciones posteriores. Lo anterior, requiere una necesaria adecuación y reestructuración, de lo contrario, la contratación electrónica o sus manifestaciones masivas, como el cibermonday o el black Friday, podrían resultar poco beneficiosos desde el punto de vista de la tutela efectiva analizada.

\section{BIBLIOGRAFÍA CITADA}

Aimone Gibson, Enrique (2013): Protección de los derechos del consumidor (Santiago de Chile, LegalPublishing, Thomson Reuters).

Barcia Lehmann, Rodrigo (2012): "Estudio sobre la prescripción y caducidad en el derecho de consumo", Revista Chilena de Derecho Privado, No 19: pp. 115-163.

Barrientos Camus, Francisca, De la Maza Gazmuri, Iñigo, Pizarro Wilson, Carlos (2013): Consumidores (Santiago de Chile, Abeledo Perrot, Thomson Reuters).

Barrientos Camus, Francisca (2016): La garantía legal (Santiago de Chile, Thomson Reuters).

Barrientos Camus, Francisca (2018): "Intento de configuración de un concurso de normas por entregas defectuosas en la Ley de Consumo y el código civil chilenos", en VIDAL Olivares, Álvaro y Momberg Uribe, Rodrigo (edit.), Cumplimiento especifico y ejecución forzada del contrato. De lo sustantivo a lo procesal (Valparaíso, Ediciones Universitarias Valparaíso) pp. 345-360.

Corral Talciani, Hernán (1999): “Ley de Protección al consumidor y responsabilidad civil por productos y servicios defectuosos", Cuadernos de extensión de la Facultad de Derecho, monográfico sobre "Derecho del consumo y protección al consumidor. Estudios sobre la ley No 19.496 y las principales tendencias extranjeras" (CORRAL TALCiAni, Hernán ed.), Universidad de Los Andes, No 3: pp. 163-211.

Corral Talciani, Hernán (2006): "La responsabilidad por incumplimiento y por productos peligrosos en la ley de protección de los derechos de los consumidores", Cuadernos de extensión de la Facultad de Derecho, monográfico sobre "La protección de los derechos de los consumidores en Chile. Aspectos sustantivos y procesales luego de la reforma contenida en la Ley 19.955 de 2004" (Baraona GonZÁlez, Jorge y Lagos Villarreal, Osvaldo edit.), Universidad de Los Andes, No 12: pp. 95-110.

Corral Talciani, Hernán (1999): "Ley de Protección al consumidor y responsabilidad civil por productos y servicios defectuosos”, en Corral, Hernán (edit.), Derecho del consumo y protección jurídica, Cuadernos de Extensión Jurídica No 3 (Santiago, Universidad de los Andes, Facultad de Derecho) pp. 163-212.

Corral Talciani, Hernán (2011): Responsabilidad por productos defectuosos (Santiago de Chile, Abeledo Perrot, Legal Publishing).

Escobar Ruiz, Jorge (2004): "Aspectos tributarios de las indemnizaciones de perjuicios"; Revista de Derecho del Consejo de Defensa del Estado, No 12: pp. 73-83.

Ferrante, Alfredo (2017): "Consumidor y doble finalidad en la utilización del bien”, Revista Chilena de Derecho Privado, No 28: pp. 273-279.

Ferrante, Alfredo (2018A): "Una revisión de los remedios del consumidor chileno en la compraventa con disconformidad a partid de la diferencia entre obligación y garantía", Revista de derecho Privado (Universidad externado), No 35: pp. 165-201. 
Ferrante, Alfredo (2018B): “¿El contratante de tiempo compartido es consumidor? avance crítico sobre la definición de consumidor chileno y el ámbito objetivo de aplicación de la ley", Revista Boliviana de Derecho, No 26: pp. 438-467.

Ferrante, Alfredo (2018C): "el inicio del cómputo del plazo para el ejercicio de la responsabilidad contravencional relativa a la garantía legal", Revista Boliviana de Derecho No 30: pp. 241-250.

Fernández Fredes, Fernando (2003): Manual de derecho chileno de protección del consumidor (Santiago de Chile, LexisNexis).

Momberg Uribe, Rodrigo (2013): “Art. 1 No 1”, en Pizarro Wilson, Carlos, De la Maza Gazmuri, Iñigo (dirs.), Barrientos Camus, Francisca. (edit.). Derecho de los Consumidores. 2a ed. (Santiago de Chile, Legal Publishing, Thomson Reuters) pp. 3-16.

Montecinos Araya, Jorge (2007): "Aspectos tributarios de las indemnizaciones civiles", GuZmán Brito, Alejandro (edit.): Estudios de Derecho Civil III, Jornadas nacionales de Derecho Civil (Santiago de Chile, Legal Publishing) pp. 891-909.

Nasser Olea, Marcelo (2013): “Art. 21” en Pizarro Wilson, Carlos y De la Maza Gazmuri Iñigo (Dir.), Barrientos Camus, Francisca (coord.), La protección de los Derechos de los consumidores (Santiago de Chile, Thomson Reuters) pp. 539-552.

Pinochet Olave, Ruperto (2004): "La formación del consentimiento a través de las nuevas tecnologías de la información. Parte I: la oferta electrónica", Revista Ius et Praxis, vol. 10, No 2: pp. 267-320.

Pinochet Olave, Ruperto (2005): "La formación del consentimiento a través de las nuevas tecnologías de la información. Parte II: la aceptación electrónica” Revista Ius et Praxis, vol. 11, No 1: pp. 55-92.

Pinochet Olave, Ruperto (2005): "La formación del consentimiento a través de las nuevas tecnologías de la información. Parte III: momento de formación del consentimiento electrónico", Revista Ius Et Praxis, vol. 11, № 2: pp. 273-302.

Pinochet Olave, Ruperto y Aguirre Veloso Patricio (2006): "La formación del consentimiento a través de las nuevas tecnologías de la información. Parte IV: El lugar de formación del consentimiento electrónico, Revista Ius Et Praxis, vol. 12, No 1: pp. 215-231.

Pinochet Olave, Ruperto (2013A): “Art. 3 bis” en Pizarro Wilson, Carlos y De la Maza Gazmuri Iñigo (Dir.), Barrientos Camus, Francisca (coord.), La protección de los Derechos de los consumidores (Santiago de Chile, Thomson Reuters), pp. 166-182.

Pinochet Olave, Ruperto (2013B): "Modificación unilateral del contrato y pacto de autocontratación: dos especies de cláusulas abusivas a la luz del derecho de consumo chileno. Comentario a la sentencia de la Excma. Corte Suprema de 24 de abril de 2013” Revista Ius Et Praxis, vol. 19, No 1: pp. 365-378.

Pizarro Wilson, Carlos y De la Maza Gazmuri Iñigo (Dir.), Barrientos Camus, Francisca (coord.) (2013): La protección de los Derechos de los consumidores (Santiago de Chile, Thomson Reuters).

Prado López, Pamela (2013): "Art. 3 bis" en Pizarro Wilson, Carlos y De la Maza GazMURi Iñigo (Dir.), BarRientos Camus, Francisca (coord.), La protección de los Derechos de los consumidores (Santiago de Chile, Thomson Reuters) pp. 151-165. 


\section{NORMAS JURÍDICAS CITADAS}

Código Civil

Decreto Ley No 825 (31/12/1974) Ley sobre impuesto a las ventas y servicios

Decreto Supremo No 55 de Hacienda (02/02/1977) Reglamento de la Ley sobre impuestos a las ventas y servicios

Ley No 19.496 (07/03/1997) Normas sobre protección de derecho de los consumidores.

Ley No $19.983(15 / 12 / 2004)$ Regula la transferencia y otorga mérito ejecutivo a copia de la factura.

\section{JURISPRUDENCIA CITADA}

Easton Muebles Limitada con AAA2K Softram Computación LtdDa. (2010): Corte de Apelaciones de San Miguel, 8 de octubre de 2010, Rol No 674-2010, en Vlex, Código de búsqueda 226624095.

Castillo Acuña Luis con Automotora Prime (2011): Corte de Apelaciones de Antofagasta, 3 de febrero de 2011, Rol No 148-2010, en Vlex, Código de búsqueda 339912818.

FundaCión EDUCACIÓN COLEGIO MAdRES DOMINICAS CON ELECTRODIESEL O LECTRO-DIESEL LTDA. (2011): Corte de Apelaciones de Temuco, 26 de enero de 2011, Rol No 14522010, en Vlex, Código de búsqueda 339819914.

SERVicio NACIONAL DEL Consumidor con ComerCializadora S.A. (2012): Corte de Apelaciones de Santiago, 7 de diciembre de 2012, Rol No 2661-2011, Thomson Reuters, Código de búsqueda CL/JUR/2729/2012.

Ramón Zambrano Mardones con Óptica Rotter y Krauss Limitada (2014): Corte de Apelaciones de Concepción, 13 de abril de 2015, Rol No 440-2014, en Thomson Reuters, Código de búsqueda CL/JUR/2067/2015.

Luis Pacheco Díaz con Cencosud Retail S.A. (2016): Corte de Apelaciones de Valparaíso, 13 de junio de 2016, Rol No 139-2016, en Vlex, Código de búsqueda 646930113.

isaías W. Maldonado ARavena con Sebastián Flores Cañas (2016): Corte de Apelaciones de Valdivia, 8 de julio de 2016, Rol No 34-2016, en Vlex, Código de búsqueda 646969417.

Schwarzhaupt Gueneau de Mussy Úrsula, Puyol Crespo Jaime y Feuerhake Molina Cecilia CON Comercializadora El Regue Limitada (2016): Corte de Apelaciones de Santiago, 27 de julio de 2016, Rol No 5-2016, en Vlex, Código de búsqueda 647744397.

Ilustre Municipalidad del Carmen contra CECOR S.A. (2016): Corte de Apelaciones de Chillán, 17 de agosto de 2016, Rol No 30-2016, en Vlex, Código de búsqueda 647348513.

Zepeda Duhalde, Marna con Viajes Falabella S.A. y otro (2017): Corte de Apelaciones de Antofagasta, 9 de enero de 2017, Rol No 168-2016, en Vlex, Código de búsqueda 658147677.

Viviana Bustos Guzmán con Automotora Gildemeister S.A. (2017): Corte de Apelaciones de Iquique, 31 de enero de 2017, Rol No 79-2016, en Vlex, Código de búsqueda 664014761. 
SERNAC contra COMERCIAL ECCSA S.A. (2017): Corte Suprema, 2a sala, de 8 de marzo de 2017, rol No 1722/2017, Vlex, Código de búsqueda 670924205.

\section{OTRAS REFERENCIAS}

Circular SII, No 103 (14 de noviembre de 1979) disponible en http://www.sii.cl/documentos/circulares/1979/circu103a.htm, fecha de consulta 11 de noviembre de 2018.

Circular SII No 62 (28 de agosto de 1980), disponible en http://www.sii.cl/documentos/ circulares/1980/circu62a.htm, fecha de consulta 11 de noviembre de 2018.

Consulta SII, Identificador 001.030.1060.008 (24 de octubre de 2018), disponible en http://www.sii.cl/preguntas_frecuentes/iva/001_030_1060.htm, fecha de consulta 11 de noviembre de 2018.

Oficio de la Subdirección normativa SII No 157 (20 de enero de 2016), en http://www. sii.cl/pagina/jurisprudencia/adminis/2016/ventas/ja157.htm, fecha de consulta $11 \mathrm{de}$ noviembre de 2018.

Oficio de la Subdirección normativa SII No 2919 (9 de junio de 2006), http://www.sii. $\mathrm{cl} /$ pagina/jurisprudencia/adminis/2006/ventas/ja2919.htm, fecha de consulta 11 de noviembre de 2018.

ResoluCIÓn EXENTA SII No 5 (22 de enero de 2015), disponible en http://www.sii.cl/documentos/resoluciones/2015/reso05.pdf, fecha de consulta 11 de noviembre de 2018.

Resolución EXENTA SII No 51 (910 de junio de 2015), disponible en http://www.sii.cl/ documentos/resoluciones/2015/reso51.pdf, fecha de consulta 11 de noviembre de 2018 .

RESOluCión EXENTA SII No 52 (10 de junio de 2015), disponible en http://www.sii.cl/documentos/resoluciones/2015/reso52.pdf, fecha de consulta 11 de noviembre de 2018.

RESOlUCIÓn EXENTA SII No 66 (31 de julio de 2015), disponible en http://www.sii.cl/documentos/resoluciones/2015/reso66.pdf, fecha de consulta 11 de noviembre de 2018. 